\title{
Hydroclimate variability in Scandinavia over the last millennium - insights from a climate model-proxy data comparison
}

\author{
Kristina Seftigen $^{1,2}$, Hugues Goosse ${ }^{2}$, Francois Klein ${ }^{2}$, and Deliang Chen ${ }^{1}$ \\ ${ }^{1}$ Regional Climate Group, Department of Earth Sciences, University of Gothenburg, Gothenburg, Sweden \\ ${ }^{2}$ Georges Lemaître Centre for Earth and Climate Research (TECLIM), Earth and Life Institute, \\ Université catholique de Louvain (UCL), Leuven, Belgium
}

Correspondence: Kristina Seftigen (kristina.seftigen@gvc.gu.se)

Received: 14 March 2017 - Discussion started: 5 April 2017

Revised: 26 September 2017 - Accepted: 11 October 2017 - Published: 18 December 2017

\begin{abstract}
The integration of climate proxy information with general circulation model (GCM) results offers considerable potential for deriving greater understanding of the mechanisms underlying climate variability, as well as unique opportunities for out-of-sample evaluations of model performance. In this study, we combine insights from a new tree-ring hydroclimate reconstruction from Scandinavia with projections from a suite of forced transient simulations of the last millennium and historical intervals from the CMIP5 and PMIP3 archives. Model simulations and proxy reconstruction data are found to broadly agree on the modes of atmospheric variability that produce droughts-pluvials in the region. Despite these dynamical similarities, large differences between simulated and reconstructed hydroclimate time series remain. We find that the GCM-simulated multi-decadal and/or longer hydroclimate variability is systematically smaller than the proxy-based estimates, whereas the dominance of GCMsimulated high-frequency components of variability is not reflected in the proxy record. Furthermore, the paleoclimate evidence indicates in-phase coherencies between regional hydroclimate and temperature on decadal timescales, i.e., sustained wet periods have often been concurrent with warm periods and vice versa. The CMIP5-PMIP3 archive suggests, however, out-of-phase coherencies between the two variables in the last millennium. The lack of adequate understanding of mechanisms linking temperature and moisture supply on longer timescales has serious implications for attribution and prediction of regional hydroclimate changes. Our findings stress the need for further paleoclimate data-model intercomparison efforts to expand our understanding of the dynamics of hydroclimate variability and change, to enhance
\end{abstract}

our ability to evaluate climate models, and to provide a more comprehensive view of future drought and pluvial risks.

\section{Introduction}

Among the current key priorities in climate research is a more comprehensive understanding of changes in regionalto continental-scale hydroclimate in response to rising levels of atmospheric greenhouse gases on timescales ranging from decades to centuries (Wu et al., 2013; Hegerl et al., 2015). Delineating the role of internal variability and natural forcing, and their contribution to the anthropogenically forced 20th century climate (Zhang et al., 2007; Sarojini et al., 2016), is immensely important for attributing past and predicting future trajectories in the hydrological cycle and for strategic approaches to adaptation and planning. Sparse observational evidence limits possibilities of providing tight constraints on the long-term behavior of the climate system. The longest instrumental records ( $\sim 150-200$ years) are too short to fully sample modes of variability that are either rare or occur on multi-decadal to centennial timescales. This motivates the development of paleoclimatic proxy reconstructions, which extends the observational baseline into the longer spectrum of climate variability and provides a framework to consider both internal and forced climate changes.

Considerable advancements have recently been made in developing tree-ring estimates of late Holocene hydroclimate variability across Scandinavia (Seftigen et al., 2014; Cook et al., 2015). Being located in the high-latitude boreal zone, Scandinavia is well suited for dendroclimatological studies 
and has a long tradition of climate and environmental research using tree-ring data (Linderholm et al., 2010). The use of tree-ring proxy evidence to study natural hydroclimate variability has however long been secondary when compared to the scientific attention focused on providing local and regional reconstructions (Gunnarson et al., 2011; Esper et al., 2012; McCarroll et al., 2013; Linderholm et al., 2014) and methodologies (Björklund et al., 2012, 2014) to study temperature variability over the last several millennia. Much of the tree-ring research at moisture-limited sites has until recently been limited to a handful of exploratory papers (Helama and Lindholm, 2003; Linderholm et al., 2004; Jönsson and Nilsson, 2009; Drobyshev et al., 2011; Seftigen et al., 2013) that generally develop one or a few chronologies to provide local precipitation and drought histories. These studies, together with a steadily growing collection of highlatitude moisture sensitive tree-ring records (e.g., Seftigen et al., 2015), now serve as a basis for new possibilities to expand the detail and accuracy with which the history of northern European moisture conditions can be described.

A recent milestone in the field includes the development of the "Old World Drought Atlas" ("OWDA", Cook et al., 2015), a set of tree-ring reconstructed year-to-year maps that provide temporal and spatial details of droughts and wetness in the last millennium across Europe, including Scandinavia. The OWDA has been used to elucidate hydroclimatic blueprints of the Medieval Climate Anomaly (MCA, $\sim 1000-1200 \mathrm{CE}$ ). Aligning with prior findings (Helama et al., 2009), the atlas reveals the occurrence of so-called megadroughts in large portions of continental northern central Europe and southern Scandinavia during the MCA period. Interestingly, the MCA and other "Old World" droughts seem to coincide with the timing of some severe and persistent droughts documented in the climate history of North America. While this suggests the presence of some common driving mechanisms across the North Atlantic, possibly related to variations in the Atlantic Ocean sea surface temperature (SST) and/or the North Atlantic Oscillation (Feng et al., 2011; Oglesby et al., 2012), the cause of these megadroughts remains an open question.

While the proxy reconstructions undoubtedly play a pivotal role in unraveling statistical qualities of past climate, they are, alone, not able to provide a comprehensive view of the underlying physics governing the climate system. The forced-transient simulations over the last millennium from fully coupled general circulation models (GCMs) (Taylor et al., 2012) therefore offer an important complementary approach to the empirical analyses of proxy estimates. Paleoclimate reconstructions provide an observational basis that spans beyond current climate conditions that were used in developing and tuning such numerical models, thus allowing for out-of-sample evaluations of the models' predictive power. The models, however, can be used to explore the dynamics that have driven climate variability in the past.
This paper builds on previous tree-ring analyses (Seftigen et al., 2014, 2015) and aims at employing a paleoclimate data-model comparison framework to further explore the drivers and dynamics of drought-pluvials across northern Europe. We analyze an ensemble of six state-of-theart GCMs from the Past Model Intercomparison Phase 3 (Schmidt et al., 2011 - PMIP3) and the Coupled Model Intercomparison Phase 5 (Taylor et al., 2012 - CMIP5) and compare them to a new regional tree-ring-based proxy reconstruction of drought and wetness, spanning the last millennium of the Common Era (CE). A combined data approach is used to (1) evaluate to what extent the GCMs are capable of reproducing the key features of the paleoclimate record and (2) to estimate the role of external forcing versus internal variability in driving the hydroclimatic changes regionally. The relative contribution of changes in rainfall and surface temperature on interannual and decadal or longer timescales to regional hydroclimate patterns is also briefly explored, and the ability of the CMIP5-PMIP3 models to simulate the mechanisms by which the regional hydroclimate is constrained by these two variables is evaluated. The collective proxy-model data assessment will help to increase our understanding of decadal and longer climate dynamics in regions and to evaluate the ability of the state-of-the-art GCMs to simulate realistic future hydroclimatology regionally and across a variety of different timescales.

The paper is structured as follows. Section 2 reviews the methods and describes the paleoclimate and CMIP5-PMIP3 datasets. Subsequent analyses concentrate on comparing the GCM simulations with the proxy-based hydroclimate reconstructions (Sect. 3) and delineating the role of external (Sect. 4) and internal (Sect. 5) sources of variability over the last millennium. The principal results and the implications of this study are discussed in Sect. 6.

\section{Data and methods}

\subsection{CMIP5-PMIP3 simulations}

Simulations with six models (CESM1, CCSM4, IPSLCM5A-LR, MIROC-ESM, MPI-ESM-P, BCC-CSM1-1) contributing to the Coupled and Paleo Model Intercomparison Projects Phases (CMIP3-PMIP3) (Schmidt et al., 2011; Taylor et al., 2012) have been used (Table 1). The analyses were restricted to models that have available complete monthly precipitation and temperature variables spanning the last millennium (850-1849 CE) through historical (1850-2005 CE) time intervals. The six millennium simulations were forced with reconstructed solar, volcanic, greenhouse gas (GHG) and aerosol forcing, and partly land use changes, whereas the historical simulations included natural and anthropogenic forcing (Schmidt et al., 2011; Taylor et al., 2012). Except for CESM1, the analyses were limited to the first r1ilp1 ensemble member. The Supplement (Sect. S1, Fig. S1) provides an evaluation of six selected model rainfall 

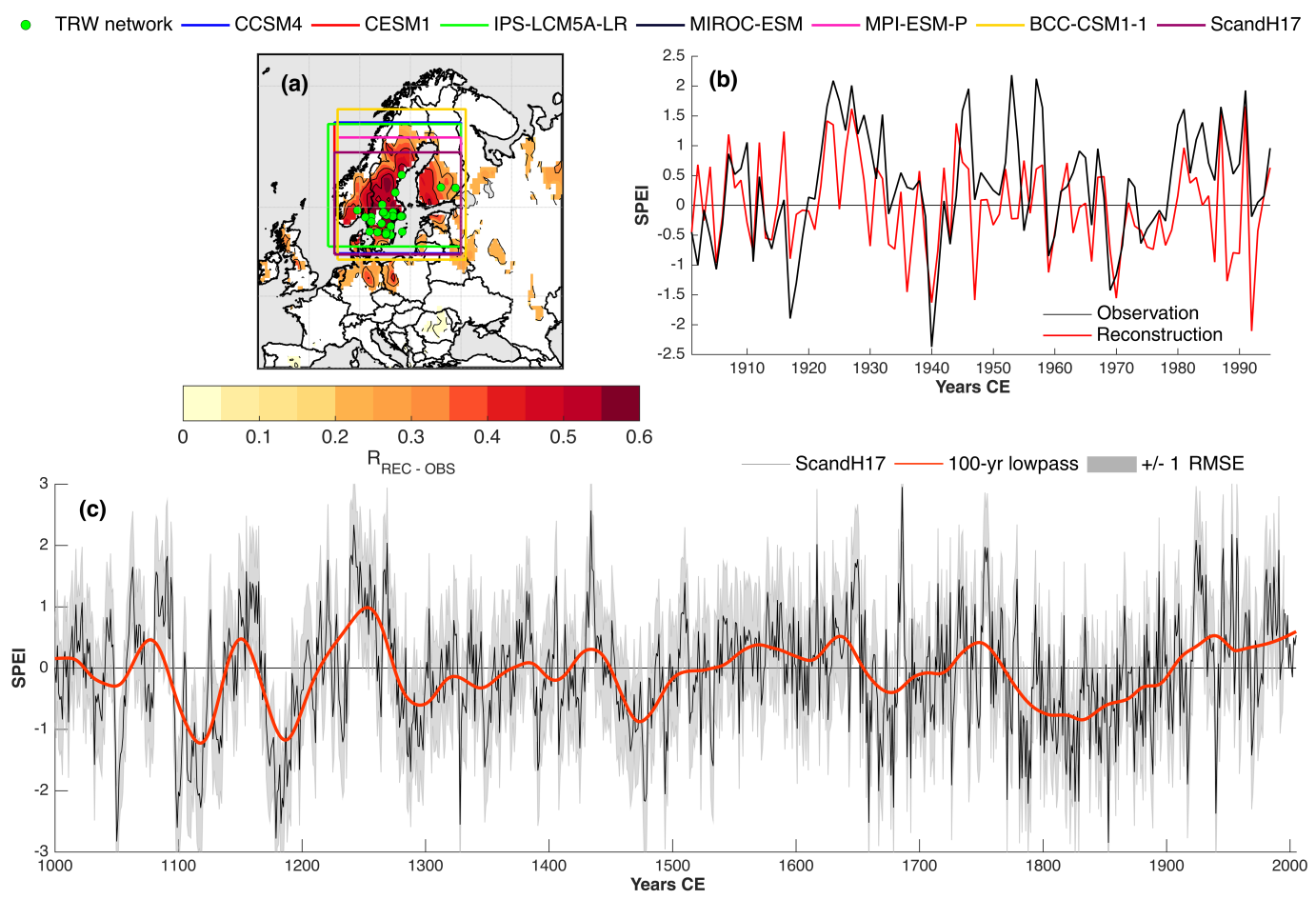

Figure 1. Average regional warm-season SPEI time series reconstructed from tree rings. (a) Location of the tree-ring network used for regional reconstruction and the extent of the CMIP5-PMIP3 model precipitation and temperature grids used to derive regional SPEI estimates. Shaded contours display the correlation $(p<0.1)$ between the tree-ring reconstruction and fields of instrumental SPEI data over the 1901-1995 period; (b) average regional reconstructed and instrumental 20th century 2-month June SPEI; (c) average regional SPEI nested reconstruction, with the \pm 1 RMSE of the regression equations outlined in grey shading. A smoothed version of the reconstruction using a 100-year loess smooth is shown in red. Reconstruction assessment metrics are provided in the Supplement (Fig. S4).

Table 1. CMIP5-PMIP3 model description.

\begin{tabular}{lrrl}
\hline Model name & $\begin{array}{r}\text { Resolution } \\
\text { (atmosphere) }\end{array}$ & $\begin{array}{r}\text { Resolution } \\
\text { (ocean) }\end{array}$ & Reference \\
\hline CCSM4 & $192 \times 288$ & $384 \times 320$ & Landrum et al. (2012) \\
CESM1 & $96 \times 144$ & $384 \times 320$ & Lehner et al. (2015) \\
IPSL-CM5A-LR & $96 \times 96$ & $149 \times 182$ & Dufresne et al. (2013) \\
MIROC-ESM & $64 \times 128$ & $192 \times 256$ & Watanabe et al. (2011) \\
MPI-ESM-P & $96 \times 192$ & $220 \times 256$ & Jungclaus et al. (2014) \\
BCC-CSM1-1 & $64 \times 128$ & $232 \times 360$ & Wu et al. (2014) \\
\hline
\end{tabular}

and temperature simulations against instrumental reference data focusing on the northern European sector.

\subsection{Proxy data}

The use of annually resolved tree-ring series in the study of past hydroclimate variations has traditionally been confined to lower-latitude arid and semiarid region, with only a few exceptions for the northern European sector. This is because the influence of moisture on tree growth generally decreases and is successively replaced by sensitivity to warm-season temperature towards northern, cooler, and wetter environments. Nevertheless, a growing body of re- search (e.g., Helama and Lindholm, 2003; Wilson et al., 2012; Seftigen et al., 2013) has established the potential to develop moisture-sensitive tree-ring chronologies in highlatitude environments if a careful selection of species and sites is made. Building upon these findings, here we analyze an existing network (Seftigen et al., 2014, 2015) of $25 \mathrm{Pi}$ nus sylvestris L. tree-ring width chronologies from across a number of dry sites in southern Scandinavia (Fig. 1). The collected trees typically grew on well-drained soils or steep south-facing slopes with warm and sunny exposure. Thus, low soil moisture availability during the growing season has been shown to be the most common growth-limiting factor in the tree-ring network (Figs. S3 and S6).

The start dates of the chronologies varied across the collection, ranging from 532 to $1790 \mathrm{CE}$ (Table 2). All chronologies extended at least to the year 1995. In order to reduce the risk of a natural and/or anthropogenic disturbance signal from inflicting non-climate noise upon the reconstruction, the tree-ring data have been standardized in previous research (Seftigen et al., 2014) by using a flexible "data-adaptive" method of standardization (Cook et al., 1995). This has limited the degree to which longer-timescale climate information can be extracted. Therefore, rather than using the already available hydroclimate reconstruction provided in Seftigen 
Table 2. Tree-ring network description.

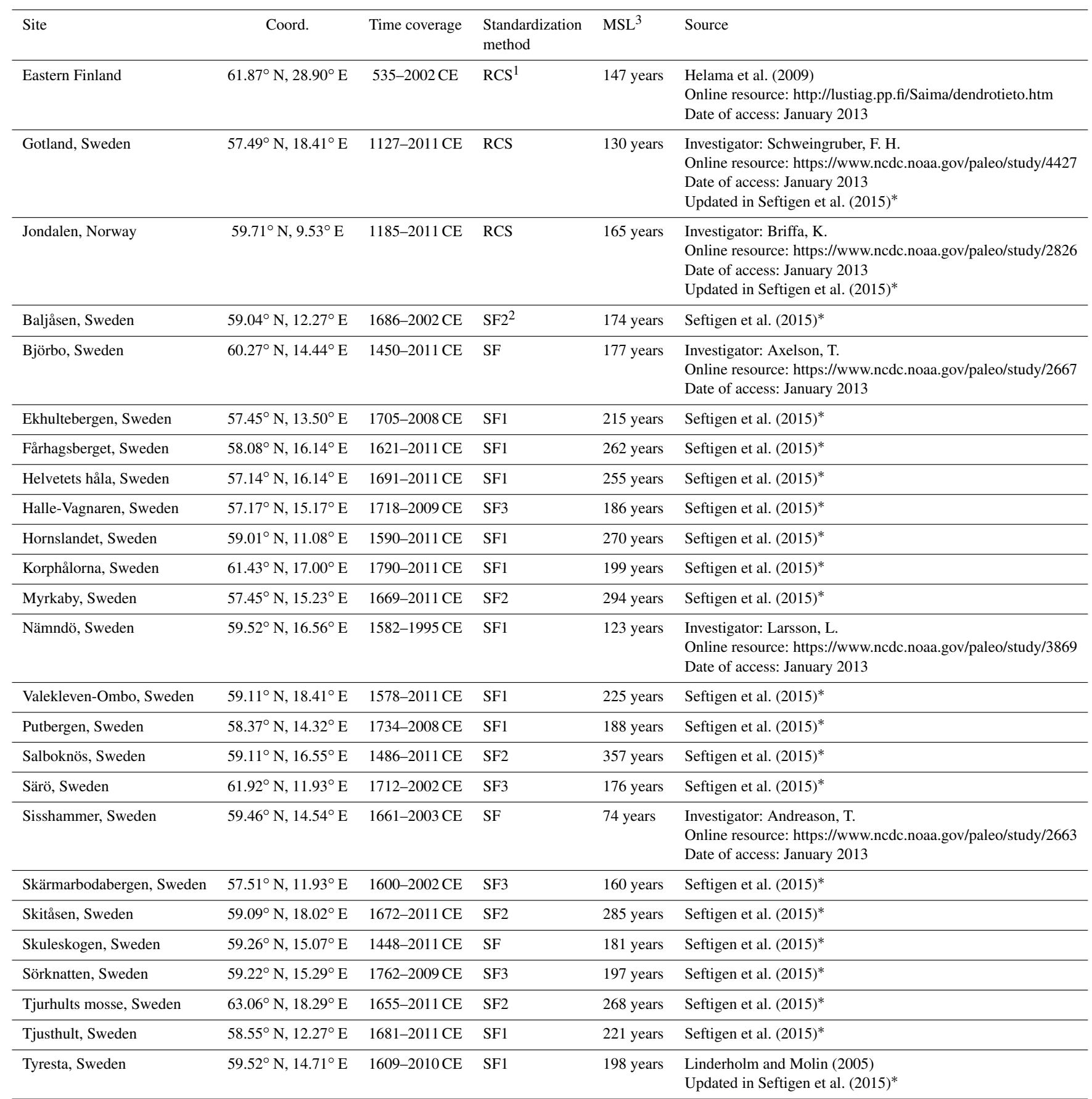

${ }^{1}$ RCS: regional curve standardization. ${ }^{2}$ SF: signal-free standardization. The number after the abbreviation indicates the PCA cluster number (Fig. S2). ${ }^{3}$ MSL: mean segment length. ${ }^{*}$ Unprocessed tree-ring chronologies are available in the Supplement.

et al. (2014), here we have reprocessed the tree-ring width (TRW) collection with the newest signal-free (SF) method of standardization (Melvin and Briffa, 2008), which has the capacity of preserving long-term variability due to climate changes. The standardization was performed with the ARSTAN software (Cook and Krusic, 2005). Chronologies combining living and historical or subfossil material were stan- dardized with a regional curve standardization (RCS) approach (Briffa et al., 1992), applying a single RCS curve without any pith-offset adjustments to detrend all series. To avoid spurious growth trends in the resulting RCS chronologies stemming from a modern sample bias (Briffa and Melvin, 2011), tree-ring datasets based only on living trees were standardized using the SF method in combination with 
an age-dependent smoothing spline applied individually to each series. Prior to the standardization, the modern chronology data were high-pass filtered and subsequently grouped by means of an S-mode principal component analysis over the common interval (1792-1996 CE). The resulting eigenvector loadings are provided in the Supplement (Fig. S2) and describe the major modes of high-frequency variability within the multiple modern chronologies composing the dataset. The subdivision of the chronologies essentially identified an east-west pattern, broadly corresponding to subregional differences in topography and climate across the study domain. This suggested that the subregional tree-growth coherence at high frequencies was driven by climate. Hence, it would be rational to expect a common, climatically induced growth variability also on the medium-frequency timescales, while any disparities in the subregional tree-growth signal are likely mostly non-climatic in origin (i.e., local site management practices, stand dynamics or other "random" sitespecific disturbances). Therefore, in order to remove or minimize undesirable non-climatic noise upon our dataset, modern tree-ring series were first merged group-wise as identified by the first four principal components and subsequently detrended as four separate "batches" using the SF method. The standard version of the resulting tree-growth indices was subsequently separated and averaged for each site to produce individual site chronologies. This procedure enabled us to retain any shared, subregional, growth-forcing signal while removing site-specific medium- to high-frequency noise.

Final data were adjusted to reduce the variance bias stemming from varying sample size trough time (Frank et al., 2006). The resulting chronologies were truncated where the expressed population signal (EPS) (Wigley et al., 1984) dropped below the 0.85 threshold, or, in the case of the longer chronologies, at year $1000 \mathrm{CE}$. The median segment length (MSL) of all the chronologies (Table 2) ranged between 74 and 357 years, and the median MSL across all sites was 197 years. Although a precise quantification of returned frequency variance in the final SF-detrended tree-ring chronologies was not straightforward, the median MSL suggested that it should be possible to use the network to reconstruct climate variability on timescales up to $\sim 200$ years.

\subsection{Regional hydroclimatology}

The CMIP5-PMIP3 inter-model spread in spatial resolution and sophistication of soil moisture schemes makes meaningful inter-model comparison difficult. To bypass some of these challenges, the standardized precipitation evapotranspiration index (SPEI) (Vicente-Serrano et al., 2013) was used to characterize the regional hydroclimatology across the study domain. The SPEI, a commonly used metric of soil moisture balance, has successfully been used as a target variable in several prior tree-ring reconstructions (e.g., Seftigen et al., $2014,2015)$. The index is not a state variable but rather an offline metric of the surface moisture balance that can be con- sistently derived across models and therefore provide standard measure of hydroclimatic variability across GCMs. The computation of the index is based on normalized monthly climatic water balance, i.e., cumulative precipitation minus potential evapotranspiration (PET), summed over multiple timescales and computed as standard deviations with respect to long-term mean (Vicente-Serrano et al., 2010). The PET was estimated here with the Thornthwaite approach (Thornthwaite, 1948). The method requires surface temperature and latitude data only and has therefore frequently been used for PET computations over the historical period. Moreover, the choice of methods is motivated by the larger confidence that is placed on GCM simulations of temperature compared to other variables (vapor pressure, wind speed, net radiation, etc.) that are required for more physically based parameterizations of PET. At each grid point, model SPEI values were derived from estimated PET and simulated rainfall over the past 1000 years and historical periods and then standardized against the 1901-2005 normalization period using the SPEI $\mathrm{R}$ package version 1.6 (Vicente-Serrano et al., 2010).

The proxy dataset was generated using a point-by-point regression (PPR) methodology that was applied to the TRW network to produce a SPEI reconstruction spanning the past millennium. The climate field reconstruction method is based on a principal component regression procedure using the TRW chronologies as potential predictors to develop a set of nested multivariate stepwise regression models (see Cook et al., 1999, for details). Here we employed the same calibration and validation scheme, predictor selection, and preprocessing steps as previously described in Seftigen et al. (2015). We performed a full period calibration over the 1901-1995 period of TRW-climate data overlap. A conventional split period calibration and validation procedure was additionally performed for an independent validation of the SPEI estimate by splitting the full calibration period into two periods of roughly equal length (1901-1948 and 1949-1995 periods) and computing and comparing validation metrics over both periods. Each nest was centered and scaled to have the same mean and variance as the observational data in the calibration period. The instrumental SPEI target field for the reconstruction was computed from the CRU TS 3.22 (Harris et al., 2014) $0.5^{\circ}$ latitude $\times 0.5^{\circ}$ longitude gridded rainfall and temperature datasets over the southern portion of Scandinavia (55-65 ${ }^{\circ} \mathrm{N}$ and $5-30^{\circ} \mathrm{E}$ ) (Fig. 1), using the same conventions as described above. Simple correlation analysis conclusively demonstrated a short-term early summer moisture sensitivity of the TRW records over most of the study domain (Fig. S3). Based on these findings, we selected June SPEI, aggregated over a 2-month timescale, as the target season data for the reconstruction. A final regional time series was averaged from grid points at which the calibration regression models explained at least $20 \%$ of instrumental variance and the reduction of error (RE) and coefficient of efficiency (CE) (National Research Council, 2006) verification metrics exceeded the generally accepted threshold value of zero across all nests 
Table 3. Event years used in the superposed epoch analysis (Fig. 4). The event lists are composed of the 20 strongest eruptions from each record.

\begin{tabular}{ll}
\hline Source & Event years (CE) \\
\hline $\begin{array}{l}\text { Gao et al. (2008) (sulfate aerosol } \\
>15 \mathrm{Tg})\end{array}$ & $1167,1176,1195,1227,1258,1284,1328,1452,1459,1584$, \\
\hline $\begin{array}{l}\text { Crowley and Unterman (2013) } \\
(\text { AOD }>0.13)\end{array}$ & $1229,1258,1259,1286,1287,1456,1457,1600,1601,1641$, \\
\hline Sigl et al. $(2015)$ (global forcing \\
$\left.<5.86 \mathrm{~W} \mathrm{~m}^{-2}\right)$ & $1695,1696,1809,1810,1815,1816,1817,1884,1992$ \\
\hline
\end{tabular}

( $N=521$ grid points). The mean tree-ring hydroclimate reconstruction (henceforth ScandH17) and the corresponding instrumental target dataset are shown in Fig. 1, and a validation of the reconstruction against 20th century instrumental data that have been withheld from the calibration is provided in the Supplement (Fig. S4). Results are variable depending on the calibration and validation period used; the validation and calibration statistics are generally stronger for the 19011948 period and substantially weaker for the $1949-1995$ period. The most recent and well-replicated nests (mid-1600s to present) generally explain the greatest amount of instrumental variance $\left(R^{2}>40 \%\right.$ for the majority of the grid points). A loss of grid cells with declining proxy availability and a drop in reconstruction skill occurs prior to the late 1400s and subsequently in the 1200 s. Point-wise correlation with the gridded instrumental SPEI dataset shows that ScandH17 is representative for a larger area in southern and central Scandinavia with a correlation "hot spot" exceeding 0.6 (Fig. 1).

\subsection{Analyses}

The new proxy-based reconstruction was used to assess the temporal evolution of droughts and pluvials over the last millennium and to elucidate the mechanisms that govern hydroclimate changes in the northern European sector ranging from interannual to multi-decadal timescales. We briefly analyze the relative role of temperature (which modulates potential evapotranspiration) and precipitation (which supplies moisture) in regional hydroclimate variability (Sect. 5). We use the last-millennium and historical CMIP5-PMIP3 simulations of temperature and precipitation. As there are no independent, annually resolved proxy reconstructions of rainfall variability currently available for the region, we only included temperature estimates in the analyses of ScandH17. For this purpose, the previously published Linderholm et al. (2014) (hereafter ScandT14) summer temperature reconstruction was used. The two reconstructions ScandH17 and ScandT14 share no common predictors and are thus fully independent, which ensures that any circular statement in the comparison can be ruled out. The ScandT14 record is based on tree-ring maximum density (MXD) and blue intensity data from northern central Scandinavia and is in terms of signal strength and preserved multi-centennial-scale variability one of the best temperature reconstructions currently available for the region.

Furthermore, we extended our analyses to the model domain using the methodology of paleoclimate data-model comparison. There were three main components to the combined approach. Firstly, we evaluated the consistency in various datasets and assessed whether the CMIP5-PMIP3 simulations have statistical properties similar to the reconstruction (Sect. 3). Spectral and spectral coherency analyses were performed in two ways. The first is the multi-taper approach (Thomson, 1982) based on four tapers, in which a Monte Carlo procedure is used to estimate phase $95 \%$ confidence limits. We also used the wavelet cohere analyses available in the Grinsted et al. (2004) MATLAB package to assess the frequency-dependent relationships and phasing between various datasets.

Secondly, we used the superposed epoch analysis (SEA) (Haurwitz and Brier, 1981) to evaluate the influence of volcanic aerosol forcing on hydroclimate, temperature, and precipitation of the Scandinavian region on interannual timescales (Sect. 4). For the last millennium, monthly mean volcanic forcing series were obtained from three different sources: Gao et al. (2008), Crowley and Unterman (2013), and Sigl et al. (2015) datasets. We note that the former two forcings have been used as the boundary conditions for the last millennium CMIP5-PMIP3 simulations. The length of the proxy and model data allowed us to include sets of the 20 largest eruptions since $1100 \mathrm{CE}$ (Table 3) from the annual forcing series to assess the mean response. For each series and eruption, anomalies for 10 post-eruption years were computed relative to a 5-year pre-eruption mean. The confidence intervals around the composite responses were determined using a Monte Carlo block resampling $(N=10000)$ of the actual event year windows (see Adams et al., 2003, for details).

Thirdly, we evaluated the skill of the models to represent the dynamics that drive the variability in hydroclimate of the Scandinavian region by establishing a link between simulated and reconstructed SPEI series and fields of mean sea level pressure (MSLP) over the Atlantic-European sector 
(a) ScandH17 vs. CMIP5/PMIP3_avg
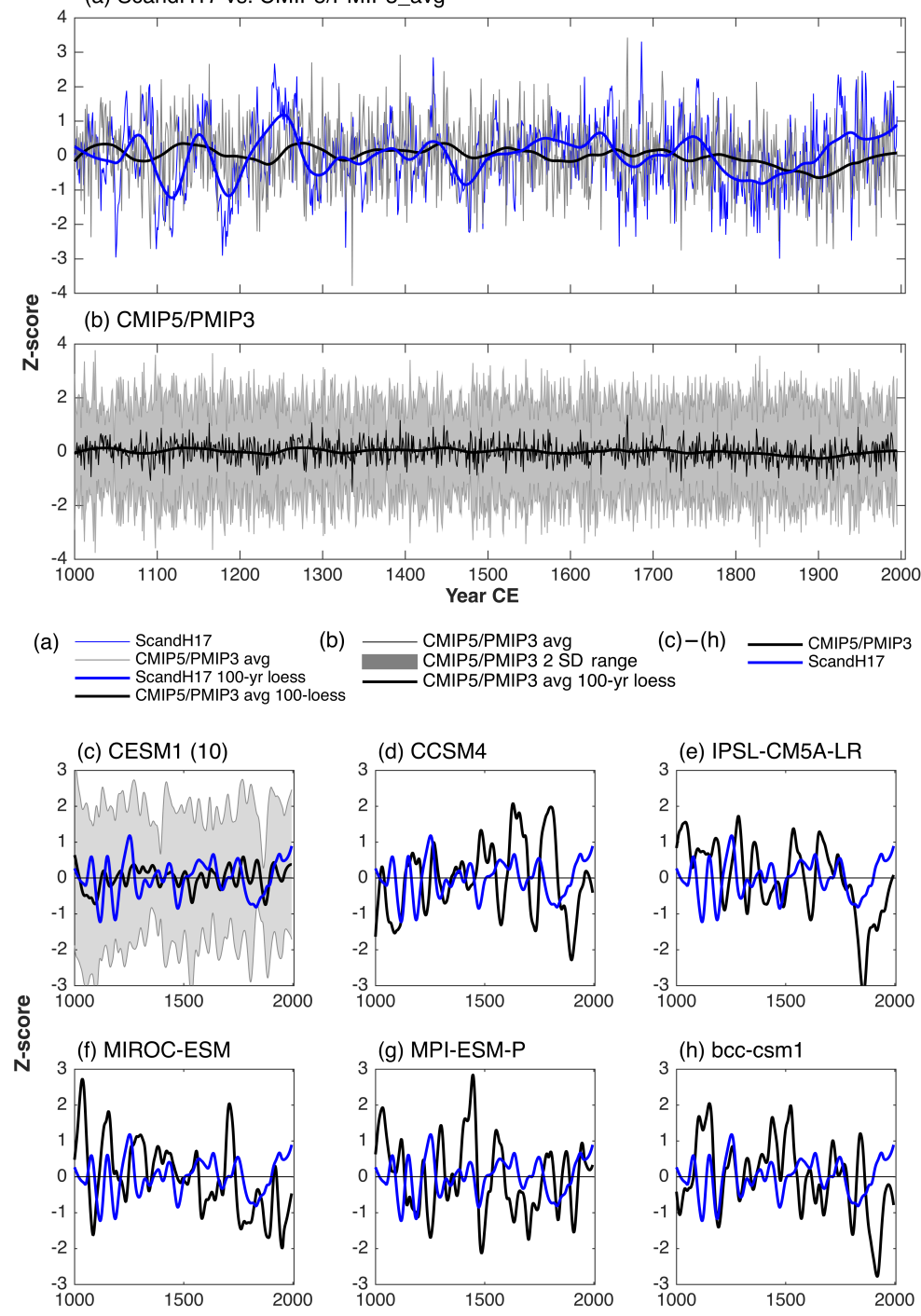

(b)

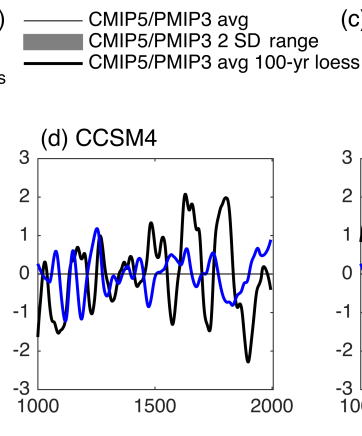

(c) - (h) CMIP5/PMIP3
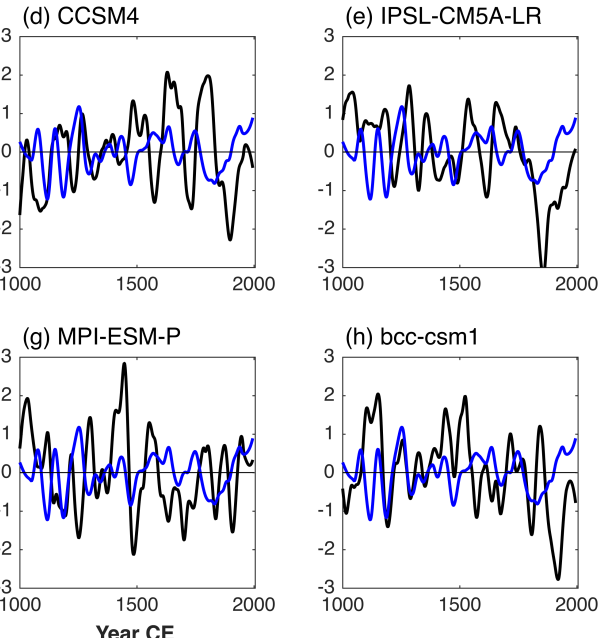

Figure 2. Comparison of reconstructed SPEI with forced model runs. (a) The reconstruction versus the mean of the six CMIP5-PMIP3 models transformed into standard normal deviates ( $z$ scores) over the 1000-1995 CE period and smoothed with a 100-year loess filter; (b) multi-model mean and the 2 standard deviation range (shading) of the six GCMs; (c) mean and 2 standard deviations (shading) of CESM1 10 smoothed and $z$-scored ensemble members (blue); (d)-(h) the reconstruction (blue) versus individual model runs (black). All time series have been smoothed with a 100-year loess filter and then $z$-scored over the 1000-1995 CE period.

(Sect. 5). Grid point correlations were computed to assess the spatial features and the strength of the teleconnections patterns over the modern era (1950-2005 CE). The analysis was also extended over the last millennium (1000-1849 CE) to investigate the nature of teleconnection stability without the influence of anthropogenic forcing. The gridded monthly instrumental HadSLP2 dataset spanning 1850-present (Allan and Ansell, 2006) was used for comparison with observed and proxy-based estimates of hydroclimate.

\section{Modeled and reconstructed hydroclimate series}

The regional warm-season hydroclimate variability averaged across the six CMIP5-PMIP3 models together with the new ScandH17 proxy reconstruction over the last millennium are shown in Fig. 2a and b. Individual model SPEI time series are displayed in Fig. 2c-h. All data have been normalized and centered over the common interval from 1000 to $1995 \mathrm{CE}$ since this first joint proxy-model comparison focuses on the common relative changes rather than on the magnitude and the absolute values. A simple visual comparison reveals that the models and the reconstruction have generally little agree- 

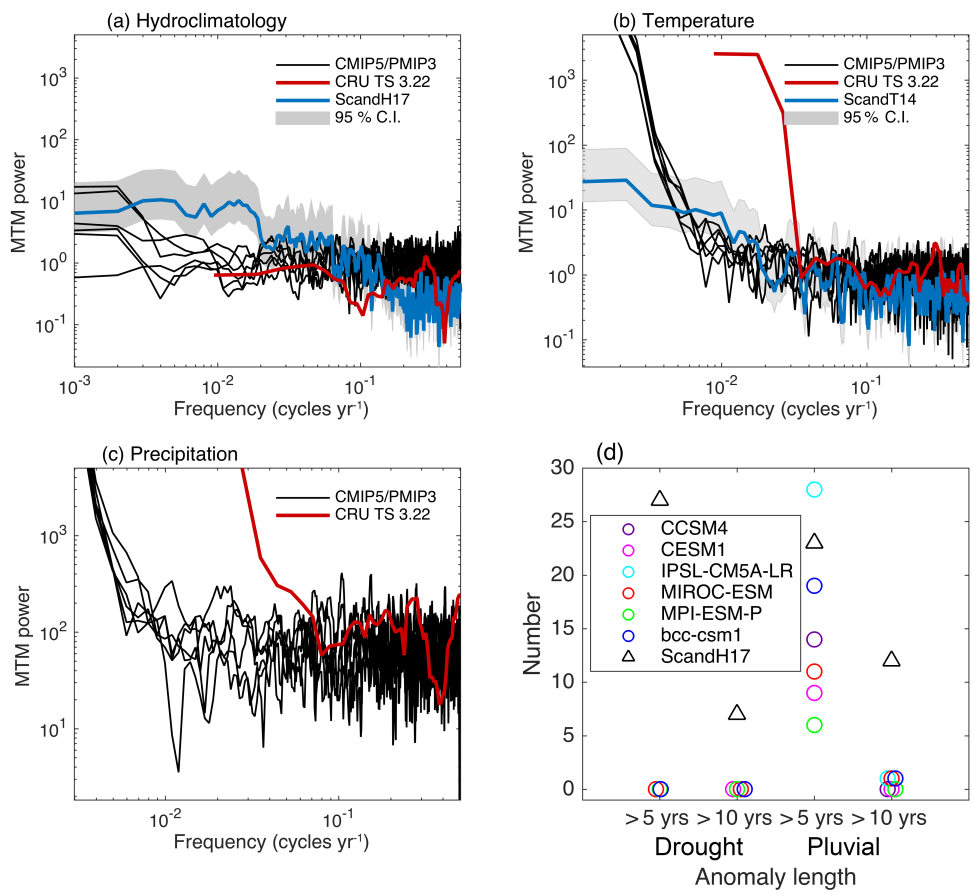

Figure 3. Spectral properties (multi-taper approach, four tapers) of (a) SPEI, (b) temperature, and (c) precipitation over the common 11001995 period. For SPEI and temperature, the spectral properties of individual GCMs (r1ilp1 ensemble) are compared to those of the tree-ring ScandH17 and ScandT14 reconstructions and regionally averaged instrumental CRU TS 3.22 data. Shaded areas show the $95 \%$ confidence interval of the reconstruction spectra. (d) The number of droughts and pluvials in the reconstructed and simulated time series that are $>5$ and $>10$ years in duration. Spectral properties of the individual models are provided in Fig. S7.

ment in the variance structure and trends. The reconstruction is dominated by a large decadal to multi-decadal variability while the multi-model mean is relatively flat on these timescales. There are some common features in some of the GCMs and the proxy datasets though (Fig. 2c-h), e.g., the drying in the 19th century, but these are rare when the full millennium is considered and likely occur by chance. The historical interval in the proxy record is characterized by a drought in the mid-1800s and a gradual increase in wetness over the 20th century, while, with the exception of a short, dry episode in the early 1900s, there is no long-term trend in the multi-model mean over the modern era.

The very low correlation on interannual timescales is to be expected, as the internal variations in the various records represent different realizations of the climate system, which is to a very large extent chaotic on that timescale. The response of each ensemble member to a strong external forcing applied to the model would nevertheless ideally agree (i.e., external punctual perturbations such as volcanic eruptions could induce a coherent short-term response; see Sect. 4). Averaging across models or over multiple ensemble members will reduce the contribution from stochastic variability so that the remaining signal can come closer to the model response to external forcing. The comparison between ScandH17 and the multi-model assemble mean reveal, however, no statistically significant agreement between the series, neither on the in- terannual nor on decadal timescales, suggesting that the simulated hydroclimate changes are not strongly tied to exogenous forcing. Moreover, we found no statistically significant correlation between the different ensemble members in the same model (CESM1) (Fig. 2c), which is the only model that provides multiple ensemble members (the only difference among these being the air temperature at the start of each ensemble member (Otto-Bliesner et al., 2016) over the historical and past millennium intervals). The poor overlap between CESM1 ensemble members as well as the individual GCM simulations over the past millennium (despite the use of largely similar forcing series to drive the simulations) is indicative of a larger contribution from internal variability on simulated drought-pluvial occurrence than from changes in exogenous forcing.

We compare the spectral properties of the six individual CMIP5-PMIP3 models to the ScandH17 reconstruction and observational data, which allows for a general evaluation of potential frequency biases. Results indicate that the underlying spectrum of reconstructed hydroclimate variability is significantly redder on decadal and centennial timescales than indicated by the simulated SPEI (Fig. 3a and d), as has previously been noted (Ault et al., 2012, 2013). In contrast, more hydroclimate variance is concentrated on interannual timescales in the CMIP5-PMIP3 archive than in ScandH17 reconstruction. At frequency bands $<8$ years, the power 
(a) Gao et al., 2008

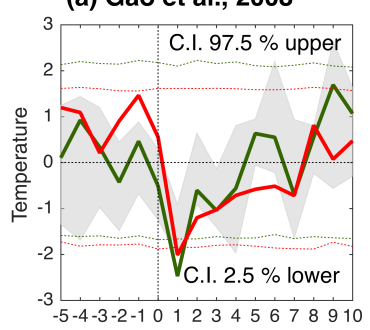

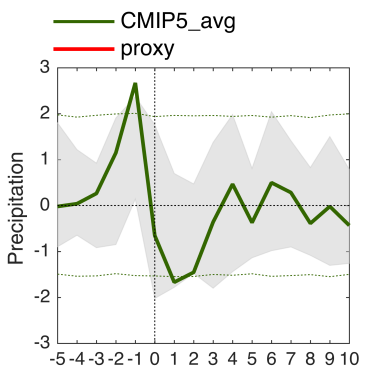

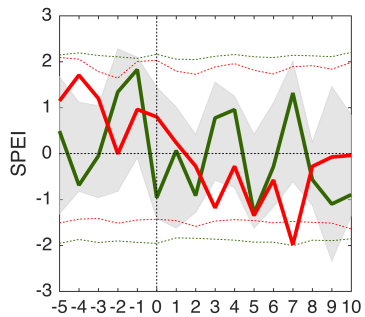

(b) Crowley and Unterman, 2013
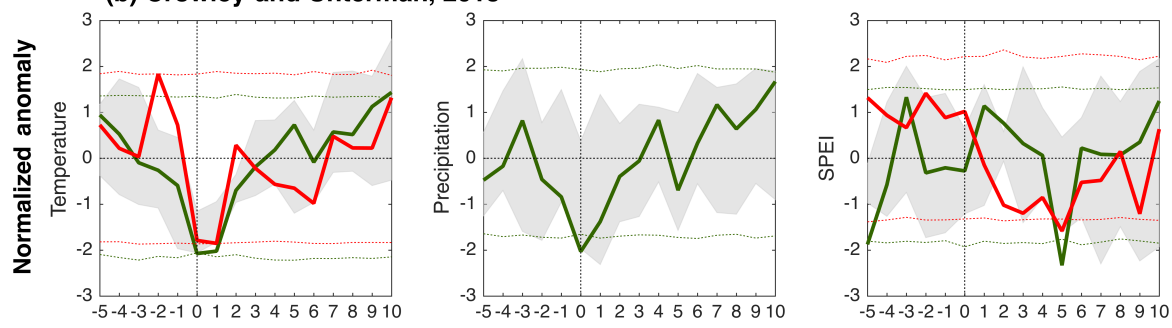

(c) Sigl et al., 2015

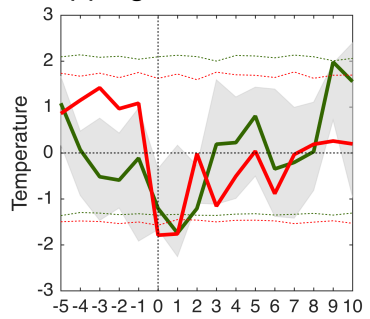

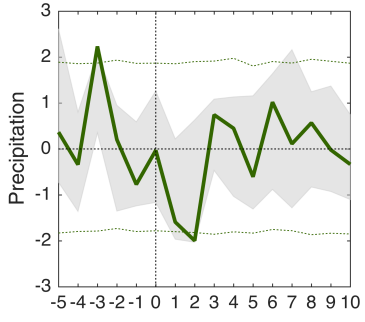

Years from event

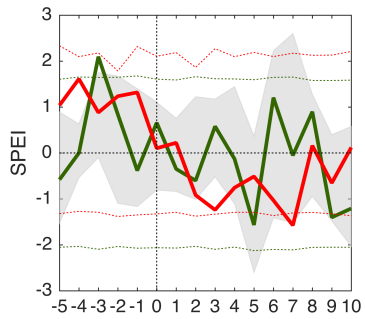

Figure 4. Modeled and reconstructed hydroclimate response to eruptions. Superposed epoch analysis using the 20 largest eruption years from (a) Gao et al. (2008), (b) Crowley and Unterman (2013), and (c) Sigl et al. (2015). Table 3 lists the event years used in the analysis. Grey shading indicates the range of modeled hydroclimate response from the six GCMs. Confidence intervals (C.I.) are derived from bootstrap resampling $(N=10000)$.

spectral range of most models is systematically above the confidence interval of ScandH17. We also consider the agreement between simulated, reconstructed (ScandT14), and instrumental temperature data in terms of their spectral properties (Fig. 3b). Although the degree of agreement is higher than for hydroclimatology and most models lie within the reconstruction confidence bands (see also Sect. S2), there are some models that have more variance than the reconstruction at periods $<10$ years.

\section{The role of volcanic forcing}

Large explosive volcanic eruptions are an important natural radiative forcing mechanism on timescales ranging from seasons to decades (Shindell et al., 2004; Gleckler et al., 2006). The imposed perturbation on the climate system by such events will depend on the nature of the eruption, the magnitude of change in the energy entering the earth's atmosphere, the background climate and internal variability, latitude, and season. Analysis of observational data (Shindell et al., 2004), tree-ring records (D'Arrigo et al., 2013), and model simulations (Anchukaitis et al., 2010) indicate a considerable spatial variability in the dynamical response of the climate system to volcanic forcing, with some regions experiencing surface and tropospheric cooling effects and other regions showing no significant change or even warming effect. Here, we assess the magnitude and timing of Scandinavian summer temperature, rainfall, and hydroclimate response to short-term radiative cooling due to volcanic aerosols.

A peak cooling is observed 1 year after the eruption, both in ScandT14 and in the CMIP5-PMIP3 composite average, for all the three forcings considered (Fig. 4). In addition, there is a significant cooling in the year of the event for the Crowley and Unterman (2013) and Sigl et al. (2015) lists. ScandT14 reveal a marginally greater cooling $\left(2.0^{\circ} \mathrm{C}\right.$, mean of the three event lists) than the model average $\left(1.8^{\circ} \mathrm{C}\right) 1$ year after the eruption. Remarkably, there is a high degree of similarity in the proxy and in the GCMs not only in terms of the signal timing and the magnitude of the cooling response but also the rate of recovery. A complete recovery after the vol- 
canic cooling is found 2 years after the eruption, independent of the forcing list. These results are generally consistent with prior studies (Fischer et al., 2007; Jones et al., 2013; McCarroll et al., 2013), highlighting the importance of explosive volcanism as an external driver of northern European temperature variability. They also provide a relevant test of the model for radiation perturbations. The agreement between the model simulations and proxy data demonstrates the credibility of the models.

Existing research on the response of high-latitude rainfall and hydroclimate to volcanism is limited (in part because high-resolution moisture-sensitive proxy records are sparse or unavailable). Fischer et al. (2007) found a weak tendency to drying conditions over southern-central Scandinavia in the summer of year 0 and year 1 after the eruption. Circulation changes to the surface cooling were shown to modulate the directly forced response. On continental and global scales, both observational and modeling studies have found a decrease in precipitation (Iles et al., 2013) and streamflow (Iles and Hegerl, 2015) in response to large explosive eruptions, particularly in climatologically humid regions (Carley and Gabriele, 2014). The short-term drying is caused by a reduction in incoming solar radiation reaching the surface, which reduces evaporation, whilst the widespread cooling stabilized the atmosphere and lowered its water holding capacity (Bala et al., 2008). Here, we apply SEA to ScandH17 and simulated SPEI and precipitation to examine the influence of volcanism on Scandinavian moisture availability. A statistically significant reduction in simulated rainfall is observed for all event lists, ranging between the year of the event (Crowley and Unterman, 2013, dataset) and up to 2 years (Sigl et al., 2015, dataset) following the eruption. We find, however, that the precipitation signal is less consistent across the six CMIP5PMIP3 models than the cooling effect observed in the simulated temperature series.

The SEA on SPEI time series reveals a statistically significant drying after large volcanism. However, the response is more muted than the responses of temperature and rainfall separately. Moreover, the agreement between proxy data and the model composite average is weak and there are large inconsistencies between the different forcing records. ScandH17 shows a progressive transition from wet conditions in the event year and preceding years to dryer conditions in the consecutive years, with significant dry anomalies 5 (Crowley and Unterman, 2013, dataset) and 7 years (Sigl et al., 2015; Gao et al., 2008, datasets) after the perturbation. For the CMIP5-PMIP3 multi-model, multi-eruption average, only the fifth year after the eruption (Crowley and Unterman, 2013, list) is found to be significantly drier than the adjacent years.

The observed weak influence of volcanic forcing on the hydroclimate of the region can be explained by various factors. For example, our results reveal that GCM-simulated post-volcanic cooling remains significant for about 2 years and matches the timescale of the post-volcanic rainfall de- crease. Since the SPEI accounts for both supply and demand changes, the net effect would be such that the temperaturedriven PET decrease counters a substantial fraction of the precipitation-driven drying, thus producing SPEI values near neutral. Furthermore, the muted response of ScandH17 may arise from autocorrelated biological memory in the TRW data (Esper et al., 2015). The high year-to-year persistence may bias its ability to estimate the abruptness and severity of climatic extremes caused by volcanic cooling. The treering MXD and the blue intensity parameters have, in contrast, been suggested to be superior to TRW for recording short-term climate perturbations (Wilson et al., 2016), which is likely the reason why the response of ScandT14 is more immediate than that of ScandH17.

\section{Internal sources of variability}

If the regional hydroclimate variability is indeed dominated by internally generated stochastic components of variability (see Sect. 3), atmospheric circulation changes can be the key process shaping regional patterns of moisture availability. Advancing our understanding of the range, stability, and strength of teleconnection behavior (defined here as the correlation between hydroclimate and MSLP over the Atlantic-European sector) and its coupling to regional hydroclimate would provide an improved understanding of drought-pluvial dynamics and associated uncertainty. In this section, we first explore major modes of atmosphere variability that impact summertime northern European hydroclimatology. We also more extensively assess the contribution of atmospheric processes (and possible land-atmosphere interactions) by investigating the couplings between hydroclimate and arguably the two most critical variables of the terrestrial climate and the hydrological cycle: precipitation and temperature.

To determine the role of teleconnections, correlation of MSLP fields with the hydroclimatic variables over the most recent 50 years of the postindustrial era were computed. Results are shown in Fig. 5. As expected, we find that atmospheric dynamics have a significant role in climate variability in the region: a strong correlation with regional hydroclimate is found when MSLP in concurrent months (i.e., MayJune) is considered. The results show that the proxy-based and CMIP5-PMIP3-simulated dynamics are largely consistent with those in the instrumental record, indicating that both the proxy and the models contain realistic teleconnections to some degree. A consistent feature across the datasets is a tripole structure that would favor increased moisture supply into the Scandinavian region. The structure is characterized by anomalous cyclonic conditions across Scandinavia and high-pressure systems extending over Iceland-Greenland and, albeit less pronounced, over European Russia-central Asia. Out of the six CMIP5-PMIP3 models, MIROC-ESM is the one showing the largest discrepancy with the major 
(a) SPEI2 observation vs. HadSLP2

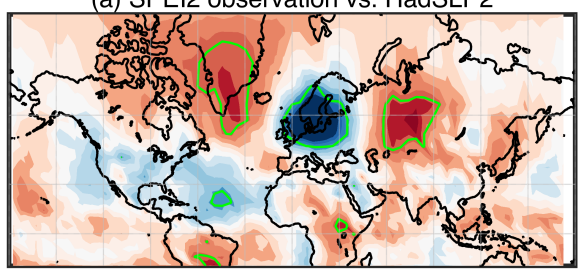

(c) CESM1

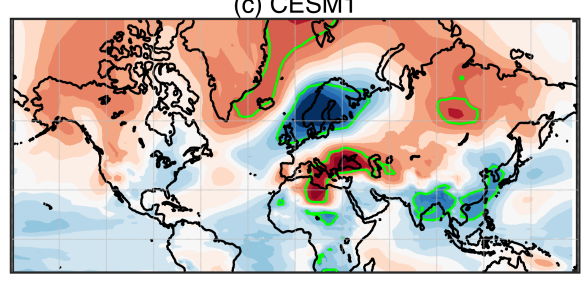

(e) IPSL-CM5A-LR

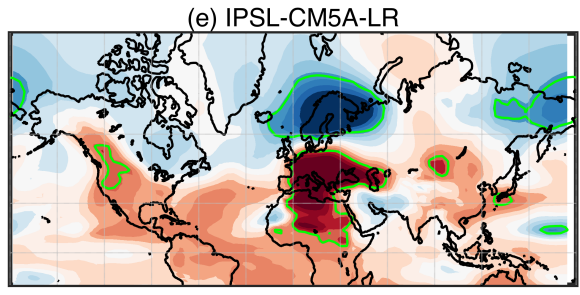

(g) MPI-ESM-P
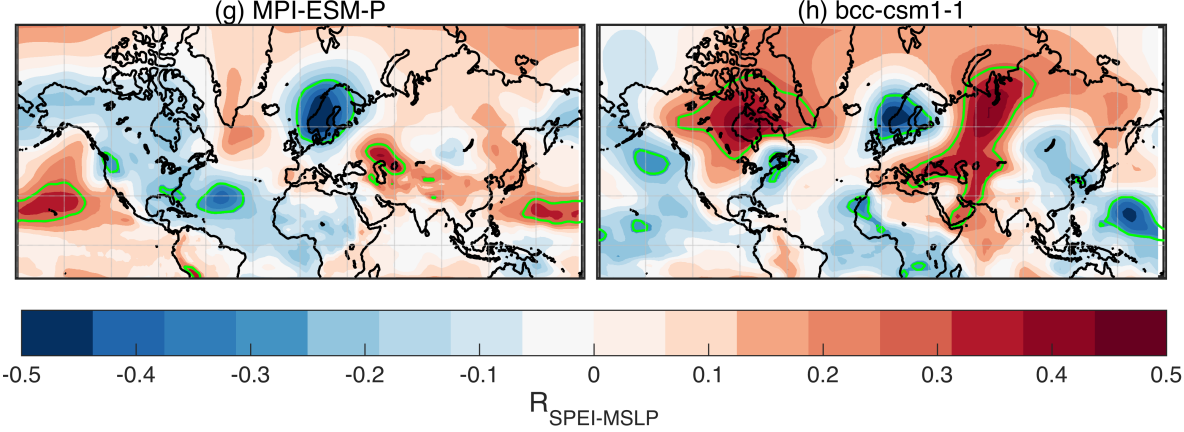

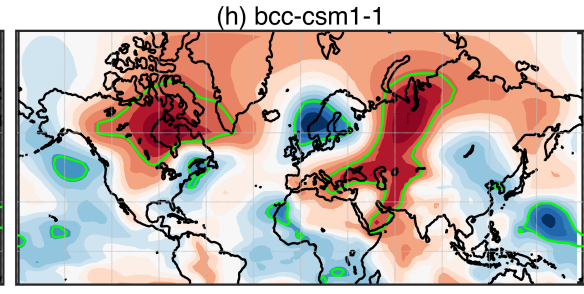

(b) ScandH17 vs. HadSLP2

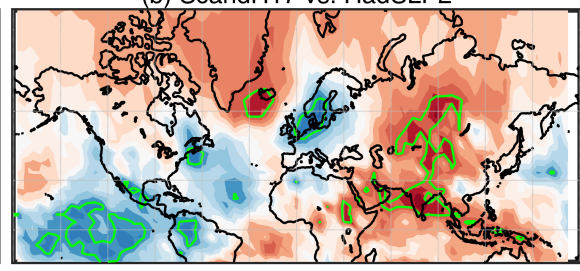

(d) CCSM4
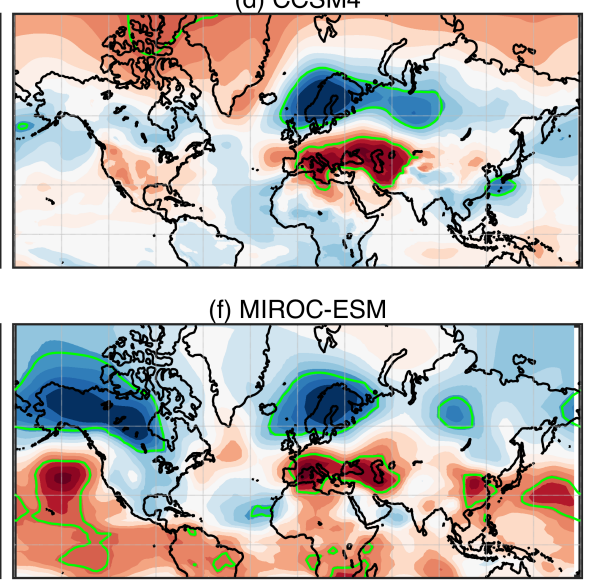

(h) bcc-csm1-1

EI-MSLP

Figure 5. Spatial distribution of the correlation coefficient of the northern European warm-season hydroclimate and mean sea level pressure (MSLP). Association between regional drought index and sea level pressure over the 1950-1995 period. Results based on (a) observations, (b) ScandH17, and (c)-(g) the model (including r1i1p1 ensemble only). Regions with significant $(p<0.05)$ correlations are outlined in green contours.

spatial features of the observed correlation map, by failing to reproduce the anticyclonic pattern over Iceland-Greenland. Additionally, MIROC-ESM and also CCSM4 show a meridional and zonal shift of the European Russia-central Asia high-pressure structure towards the Mediterranean region.

Atmospheric circulation has been identified as a key contributor to recent changes in the climate of Europe in both summer and winter (van Oldenborgh and Van Ulden, 2003; Jones and Lister, 2009). To assess the stationarity of observed MSLP patterns, the analysis was repeated for the preindustrial last millennium (1000-1849 CE; Fig. 6). The exercise was restricted to five GCMs for which simulated MSLP was available for the preindustrial era (BCC-CSM1-1 was not included). The simulated dynamical relationships were found to be largely stable for all five models, being consistent with observed correlation patterns in the modern era. This suggests a weak influence of anthropogenic forcing on the structure of the dynamical drivers of Scandinavian hydroclimate. In addition to raw data, correlation analysis with 10-year low-passed data was also completed for the preindustrial period with the purpose to elucidate the drivers of multi-decadal hydroclimate variability. We find similar, yet weaker, correlation patterns as compared to the high-frequency variations (results not shown).

Precipitation and temperature are the two key variables of the hydrological cycle. Assessing the relative contribution of these two variables to the surface moisture balance across various timescales, and the mechanisms that control and modulate it, is therefore of great interest to the study of regional processes in surface energy and water budgets. 
(a) CESM1

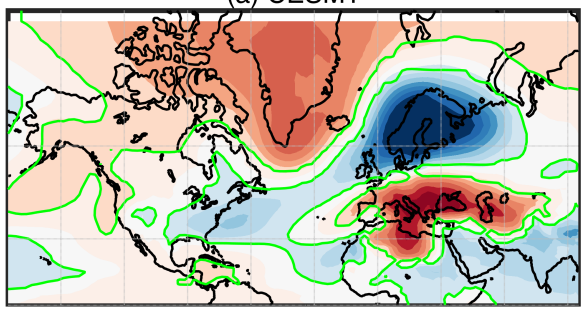

(c) IPSL-CM5A-LR

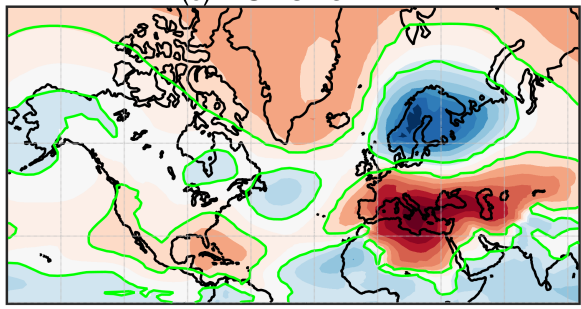

(e) MPI-ESM-P

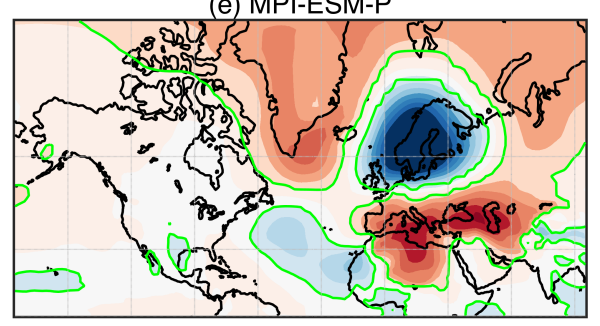

(b) CCSM4

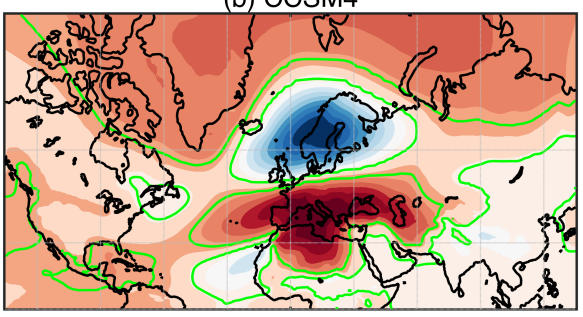

(d) MIROC-ESM

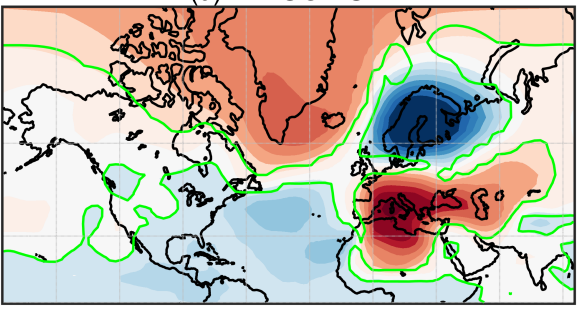

.

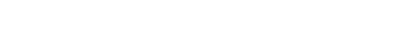

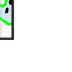



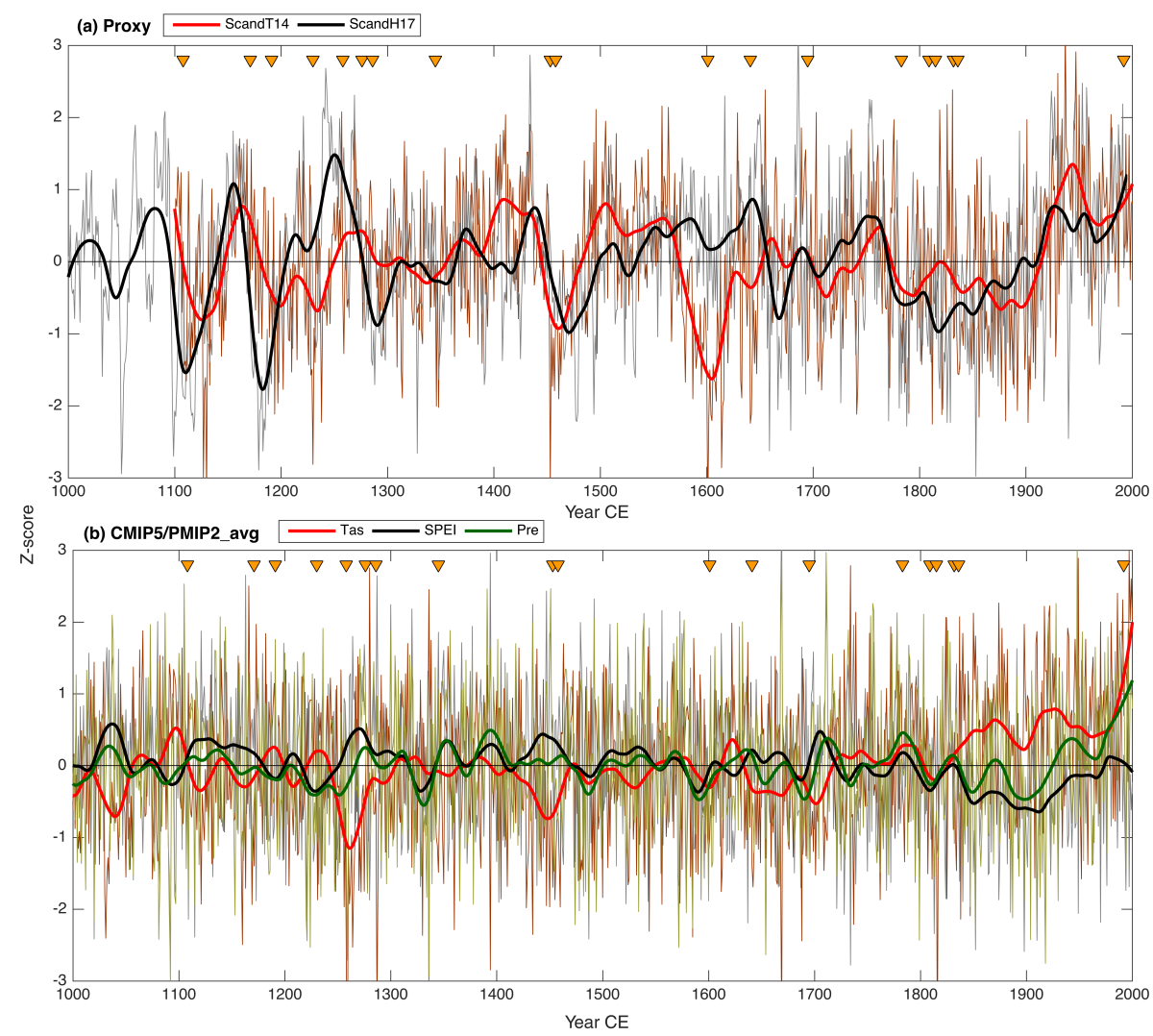

Figure 7. Time series of (a) ScandH17 and ScandT14, and (b) GCM (r1i1p1 ensemble) average temperature, precipitation and SPEI. Smoothed time-series using a 50-year loess filter are shown as thick lines. Individual model data are provided in the Supplement (Fig. S8). The years with volcanic eruptions from Table 3 are indicated by triangle glyphs.

structions share significant $(p<0.05)$ in-phase variance in multi-decadal frequency throughout most of the last millennium. The coupling seems to arise from overlap in shared frequencies at wavelengths longer than $\sim 50$ years (see Fig. 3). Interestingly, we find that the paleoclimatic evidence and the CMIP5-PMIP3 models portray a considerably different response of hydroclimate in Scandinavia to long-term temperature changes. While the proxy time series suggests that prolonged wet periods generally coincide with elevated temperatures, the majority of the CMIP5-PMIP3 models indicate that warm decades should have been dryer (Figs. 8b-h and S9).

Instrumental and paleoclimate evidence collectively suggests a time-dependent shift of the relationship between regional temperature and hydroclimate, which in turn implies that different mechanisms governing the climate system might be operating at high (interannual) and low (decadal and longer) frequencies, respectively. The previously discussed strong link between interannual regional hydroclimate variability and atmospheric pressure patterns indicates that atmospheric dynamics is likely a dominant driver of hydroclimate in the northern European sector on an interannual basis. The inverse co-variability between warm-season tem- perature and moisture supply, which is revealed by the instrumental record, may arise from synoptic-scale correspondence between reduced cloud cover-rainfall and increased incoming shortwave radiation warming the surface during clear sky conditions. In addition, soil moisture exerts a strong influence on the allocation of available energy between latent and sensible heating, especially in the warm season (Seneviratne et al., 2010). Reduced soil moisture, for example, is associated with reduced latent heat flux and thus increased sensible heating and higher air temperatures near the surface. Resulting positive feedbacks of a modified surface heat flux partitioning on cloud cover and radiation (Gentine et al., 2013) and large-scale circulation (Haarsma et al., 2009) could further strengthen the influence of rainfall variability on the thermal climate.

The positive association between temperature and SPEI that is found in the proxy records on decadal to multi-decadal timescales could imply that the long-term regional hydroclimate variability is more sensitive to changes in moisture supply (precipitation) rather than to increased evaporative demand due to warming. It may also suggest that the regional moisture balance might be favored by the Clausius-Clapyron relation (Allen and Ingram, 2002), prescribing an increase in 

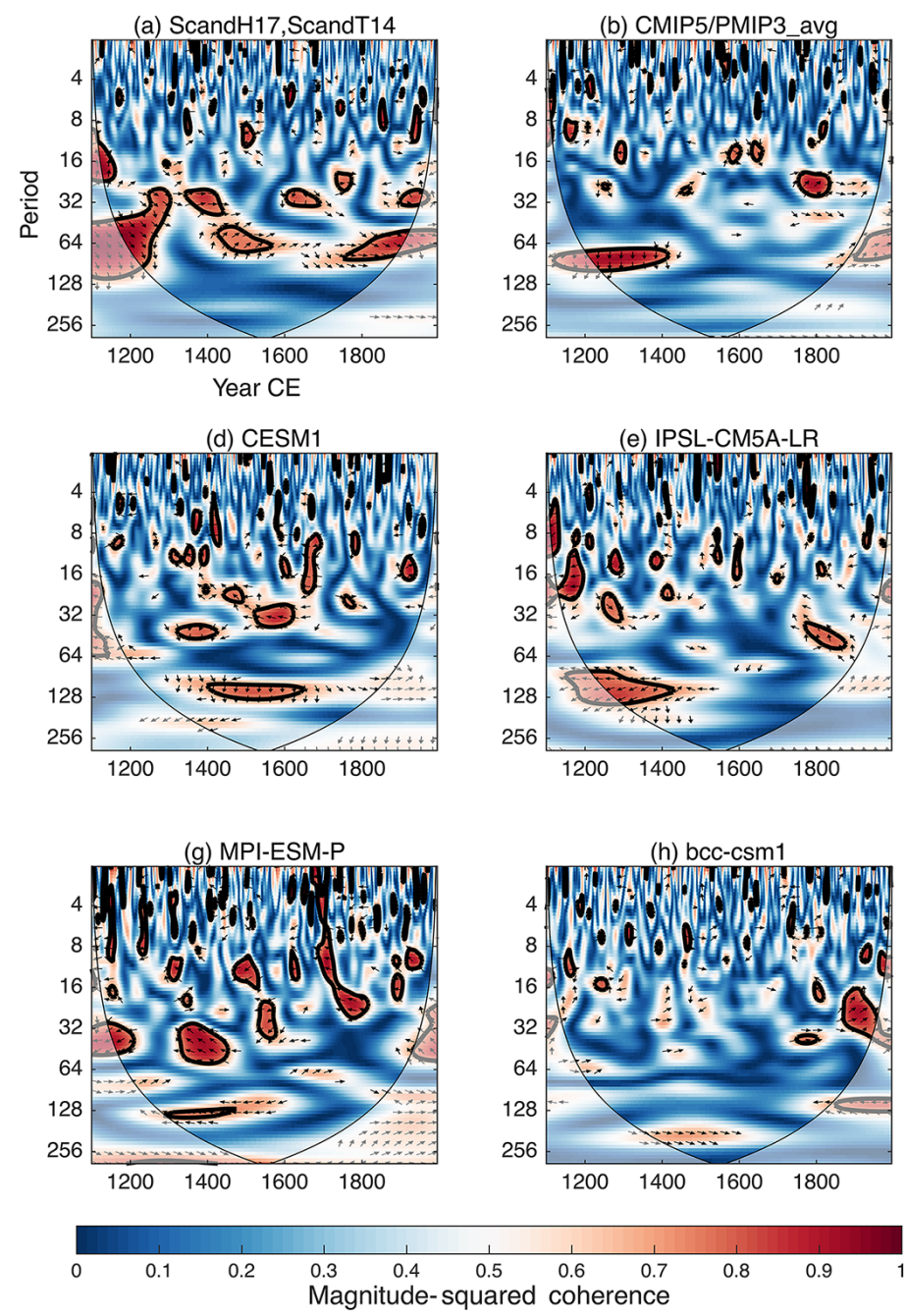

(b) CMIP5/PMIP3_avg

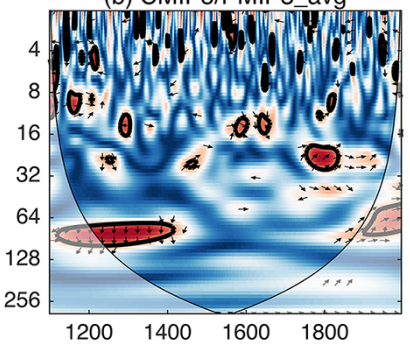

(e) IPSL-CM5A-LR

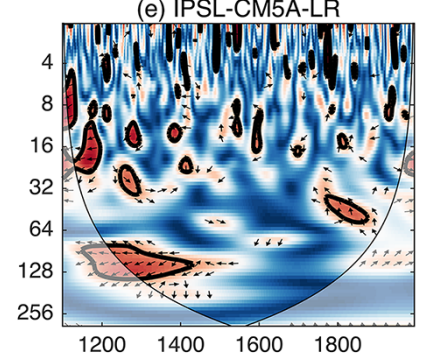

(h) bcc-csm1

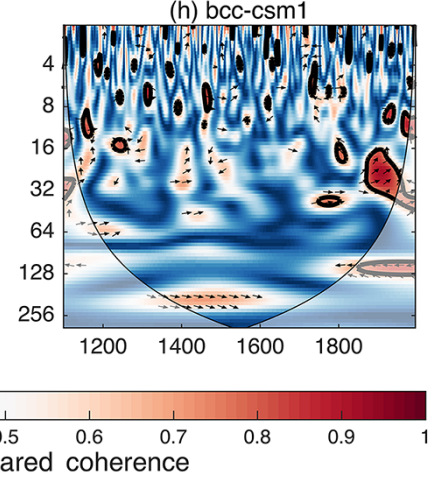

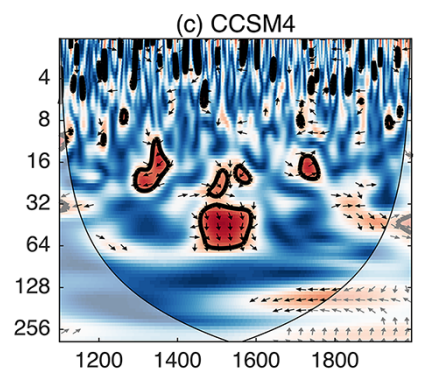

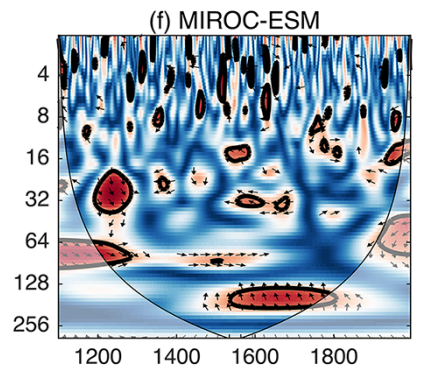

Figure 8. Squared wavelet coherence and phase between (a) ScandH17 and ScandT14, and (b)-(h) CMIP5-PMIP3 simulations of temperature and rainfall. The arrows indicate the relative phase relationship between two series; arrow pointing right (left) indicates in-phase (180 ${ }^{\circ}$ out of phase) relationship. Significant coherence at $95 \%$ significance level is shown as a thick contour.

rainfall and intensity of the hydrological cycle during warmer periods in the past millennium. This is generally referred to as the "wet-get-wetter" and "dry-get-dryer" mechanism and is attributed to thermodynamics processes (Held and Soden, 2006). In the absence of changes in atmospheric circulation, changes in net moisture supply with warming are related to change in moisture content of the atmosphere. It presupposes that existing circulations will transport more moisture into mesic regions of the globe (e.g., tropics and the midlatitudes to latitudes of the Northern Hemisphere), whilst dry regions (e.g., subtropics) will get even dryer, with the fractional change determined using the Clausius-Clapyron relation. In contrast to the proxy records, the model composite average reveals a 20th century temperature and rainfall increase yet little change in hydroclimate (Fig. 7b). The multimodel assessment implies that natural variability plays only a subsidiary role in recent changes and that forcing from an- thropogenic GHGs may have played a more important role (as previously discussed, the effect of GHG forcing on interannual teleconnection patterns in the modern era seems to be weak). Moreover, the absences of any significant trend in simulated SPEI series indicates that the gains in moisture from increased precipitation are large enough to compensate for any GHG-induced increase in PET in the postindustrial period.

\section{Summary and discussion}

This study presents the first comprehensive assessment of past variability and trends in hydroclimate of the northern European sector over the last millennium of the Common Era along with interrelated variables: precipitation, which supplies moisture, and temperature, which modulates evapotranspiration. A combined approach comparing observa- 
tional (both instrumental and proxy based) and model-based results is used for evaluation of simulated and real-world interannual to centennial climate variability and the underlying physics governing the climate system. A number of important findings emerge from the collective comparison:

1. Models and proxy data are found to broadly agree on the modes of atmospheric variability (Sect. 5) that produces droughts and pluvials in Scandinavia. Despite these dynamical similarities, large discrepancies between model simulations and the proxy reconstruction are shown to exist. The droughts and pluvials in the forced simulation are not temporally synchronous with those in the proxy record, nor do the GCM spectra agree with the proxy spectra on the amount of variance present on short and long timescales (Sect. 3).

2. The proxy data and the CMIP5-PMIP3 models reveal different effects of long-term temperature changes on summer hydroclimate in Scandinavia. According to the GCMs, prolonged droughts generally coincide with elevated temperatures. The proxy evidence, however, suggests that warm decades in the last millennium also tend to be wet decades. Although the precise reason for the model-proxy mismatch remains to be unraveled, our results suggest that spectral inconsistencies among the model and proxy datasets could be one possible explanation for the mismatch.

3. There are considerable disagreements among hydroclimate features shown by the CMIP5-PMIP3 simulations (despite the use of largely similar forcing series) (Sect. 3). Together, these results point to the possibility of a dominant influence of stochastic processes for the regional hydroclimate and/or deficiencies in the models to realistically represent relevant processes in reality.

Most notably we find clear inconsistencies between the paleoclimate record and the model spectra. On multi-decadal and longer timescales there is more variability in the proxy data than in the models. In contrast, the dominance of GCMsimulated interannual components of variability is not reflected in the proxy record. It is difficult to determine explicitly whether it is an external forcing or internal sources that drive the decadal and longer variance in the proxy reconstruction. Prior studies have highlighted the importance of external influences on regional climate variability on different timescales (e.g., Gleckler et al., 2006; Thiéblemont et al., 2015; Sigl et al., 2015). Although we find a short-term response of regional hydroclimate to volcanic perturbations (Sect. 4), multi-year anomalies in the proxy reconstruction do, however, not appear to correspond well with the epochs following the large volcanic eruptions (e.g., in the 1250s, 1450 s, and 1810s) used to force the models. Thus, we cannot rule out that the variability in the reconstruction largely arising from internal sources of variation. Consequently, if the proxy-inferred decadal to multi-decadal variability is accurate and if the variability is indeed largely unforced, then its magnitude is well beyond what any of the current generation global climate models are able to produce in the region. Underestimation of redness in the models on multi-decadal and longer timescales suggests that the GCMs might be lacking or underestimating processes important to the variability on these timescales. There are a number of recognized limitations relating to the dynamics that are relevant to the climatology of the North Atlantic-European sectors. One such example is that models have generally been unable to simulate low-frequency variability in the North Atlantic Oscillation (Osborn, 2004). They have also been shown to underestimate the periodicity of the Atlantic Multi-decadal Oscillation (Kavvada et al., 2013), which has implications for the associated hydroclimate impact on neighboring continents (Coats et al., 2015). If, however, the proxy-estimated multi-decadal and longer variability in the last millennium is forced by exogenous mechanisms, then either (1) it is a forcing component that is largely missing in the CMIP5-PMIP3 models or (2) it is a forcing component that generates a different longterm response in the models compared to the proxy view of regional hydroclimatology.

It is not possible to pinpoint which part of the disagreement between models and the proxy comes from uncertainties in the tree-ring reconstruction, deficiencies in the forcing series used to drive the models, or from deficiencies in the model. Our analyses have included precipitation simulation - a challenging variable for GCMs to simulate accurately. The coarse spatial resolution of the models gives only an approximate representation of the topographic features, which are important for regional hydroclimate. Another possibility is that the scale of the GCMs is unrepresentative of the point estimate provided by the ScandH17 reconstruction. Conversely, the mismatch between grid box and point estimates is expected to decrease on longer timescales (Jones et al., 1997). There are also limitations of the tree-ring proxy and uncertainties in the interpretation of the data that cannot be ignored. Tree rings and other biological archives may integrate climate conditions over multiple years (Zhang et al., 2015), which could potentially overestimate the ratio of lowto high-frequency variability (Franke et al., 2013). While we have been able to establish that prevailing summer moisture availability has been the main growth limitation of trees in the ScandH17 network on an interannual basis over the 20th century (Figs. S3 and S6), we cannot verify the drought-tree growth model in the pre-instrumental era or across a longer spectrum of variability. We are not able to rule out that there might have been climatic regimes in the past that would have caused a dynamical shift in the tree-growth response to climate, and potentially have called into question the uniformitarian paradigm traditionally applied in the field of dendroclimatology. These nonstationaries may include frequencydependent sensitivity of the proxy system to climate. While we are able to show that the year-to-year variability in growth 
is dominated by a moisture signal, the impact of growing season temperature on lower-frequency variations has yet to be established. In addition to these issues, there are also risks that less well known dynamics outside the climate system may introduce variability into the records on decadal and longer timescales. Advances in the mechanistic understanding of the various proxies and the processes through which they record environmental change, e.g., through development and refinement of process-based forward models (TolwinskiWard et al., 2011), is currently an emerging priority in the field.

The discrepancies in CMIP5-PMIP3-simulated and proxy-reconstructed hydroclimate variability in the last millennium is an issue that must be addressed when assessing projections of future hydroclimate change. The lack of adequate understanding for mechanisms linking temperature and moisture supply on longer timescales has important implications for future projections. Weak multi-decadal variability in models also implies that inference about future persistent droughts and pluvials based on the latest generation global climate models will likely underestimate the true risk of these events. Reconciliations for the apparent proxy-model mismatch will require efforts from the proxy, modeling, and statistics groups, including additional proxy records and refined model simulations of hydroclimate variability in the last millennium, together with the development of alternative approaches for joint proxy-model assessments. Having here provided a first comparison of reconstructed and simulated hydroclimate for Scandinavia, our future efforts will include adaptations of the data assimilation approach to paleoclimate reconstruction. Such efforts hold promise for reducing the uncertainties associated with model physics, external forcings, and internal climate variability, and ultimately help to refine our view of past and future hydroclimate changes.

Data availability. Individual unprocessed tree-ring series can be downloaded from the International Tree Ring Data Bank (http: //www.ncdc.noaa.gov/paleo/treering.html), the SAIMA Tree-Ring Data Bank (http://lustiag.pp.fi/Saima/dendrotieto.htm), or from the Supplement (see Table 2). The CMIP5-PMIP3 climate model output can be obtained though the Earth System Grid - Center for Enabling Technologies (ESG-CET) portal (http://pcmdi9. llnl.gov/). The ScandH17 hydroclimate and ScandT14 temperature reconstructions are archived through the NOAA paleoclimate database (ScandH17: https://www.ncdc.noaa.gov/paleo/study/ 23032; ScandT14: https://www.ncdc.noaa.gov/paleo/study/22692). All signal-free standardized tree-ring chronologies are provided in the Supplement.

Competing interests. The authors declare that they have no conflict of interest.
Special issue statement. This article is part of the special issue "Climate of the past 2000 years: regional and trans-regional syntheses". It is not associated with a conference.

Acknowledgements. Kristina Seftigen was supported by the FORMAS mobility starting grant for young researchers (grant no. 2014-723). Hugues Goosse is senior research associate with FRS/FNRS, Belgium. The authors wish to acknowledge the researchers who have produced and made their tree-ring chronologies available. The authors also wish to thank the World Climate Research Programme's Working Group on Coupled Modelling, which is responsible for CMIP, and to acknowledge the climate modeling groups (listed in Table 1 of this paper) for producing and making their model output available. For CMIP the US Department of Energy's Program for Climate Model Diagnosis and Intercomparison provided coordinating support and led development of software infrastructure in partnership with the Global Organization for Earth System Science Portals. The authors also wish to acknowledge Editor Helen McGregor, the $2 \mathrm{k}$ Special Issue Data Review Team, and the two anonymous reviewers for comments on this paper.

Edited by: Helen McGregor

Reviewed by: two anonymous referees

\section{References}

Adams, B. J., Mann, M. E., and Ammann, C. M.: Proxy evidence for an El Nino-like response to volcanic forcing, Nature, 426, 274-278, 2003.

Adler, R. F., Gu, G., Wang, J.-J., Huffman, G. J., Curtis, S., and Bolvin, D.: Relationships between global precipitation and surface temperature on interannual and longer timescales (1979-2006), J. Geophys. Res., 113, D22104, https://doi.org/10.1029/2008jd010536, 2008.

Allan, R. and Ansell, T.: A New Globally Complete Monthly Historical Gridded Mean Sea Level Pressure Dataset (HadSLP2): 1850-2004, J. Climate, 19, 5816-5842, https://doi.org/10.1175/jcli3937.1, 2006.

Allen, M. R. and Ingram, W. J.: Constraints on future changes in climate and the hydrologic cycle, Nature, 419, 224-232, 2002.

Anchukaitis, K. J., Buckley, B. M., Cook, E. R., Cook, B. I., D'Arrigo, R. D., and Ammann, C. M.: Influence of volcanic eruptions on the climate of the Asian monsoon region, Geophys. Res. Lett., 37, L22703, https://doi.org/10.1029/2010g1044843, 2010.

Ault, T. R., Cole, J. E., and St. George, S.: The amplitude of decadal to multidecadal variability in precipitation simulated by state-of-the-art climate models, Geophys. Res. Lett., 39, L21705, https://doi.org/10.1029/2012gl053424, 2012.

Ault, T. R., Cole, J. E., Overpeck, J. T., Pederson, G. T., St. George, S., Otto-Bliesner, B., Woodhouse, C. A., and Deser, C.: The Continuum of Hydroclimate Variability in Western North America during the Last Millennium, J. Climate, 26, 5863-5878, https://doi.org/10.1175/jcli-d-11-00732.1, 2013.

Bala, G., Duffy, P. B., and Taylor, K. E.: Impact of geoengineering schemes on the global hydrologi- 
cal cycle, P. Natl. Acad. Sci. USA, 105, 7664-7669, https://doi.org/10.1073/pnas.0711648105, 2008.

Berg, A., Lintner, B. R., Findell, K., Seneviratne, S. I., van den Hurk, B., Ducharne, A., Chéruy, F., Hagemann, S., Lawrence, D. M., Malyshev, S., Meier, A., and Gentine, P.: Interannual Coupling between Summertime Surface Temperature and Precipitation over Land: Processes and Implications for Climate Change, J. Climate, 28, 1308-1328, https://doi.org/10.1175/jclid-14-00324.1, 2015.

Björklund, J., Gunnarson, B. E., Krusic, P. J., Grudd, H., Josefsson, T., Östlund, L., and Linderholm, H. W.: Advances towards improved low-frequency tree-ring reconstructions, using an updated Pinus sylvestris L. MXD network from the Scandinavian Mountains, Theor. Appl. Climatol., 113, 697, https://doi.org/10.1007/s00704-012-0787-7, 2012.

Björklund, J., Gunnarson, B. E., Seftigen, K., Esper, J., and Linderholm, H. W.: Blue intensity and density from northern Fennoscandian tree rings, exploring the potential to improve summer temperature reconstructions with earlywood information, Clim. Past, 10, 877-885, https://doi.org/10.5194/cp10-877-2014, 2014.

Briffa, K. R. and Melvin, T. M.: A Closer Look at Regional Curve Standardization of Tree-Ring Records: Justification of the Need, a Warning of Some Pitfalls, and Suggested Improvements in Its Application, in: Dendroclimatology: Progress and Prospects, edited by: Hughes, M. K., Swetnam, T. W., and Diaz, H. F., Springer Netherlands, Dordrecht, 113-145, 2011.

Briffa, K. R., Jones, P. D., Bartholin, T. S., Eckstein, D., Schweingruber, F. H., Karlén, W., Zetterberg, P., and Eronen, M.: Fennoscandian summers from ad 500: temperature changes on short and long timescales, Clim. Dynam., 7, 111-119, https://doi.org/10.1007/bf00211153, 1992.

Carley, E. I.,and Gabriele, C. H.: The global precipitation response to volcanic eruptions in the CMIP5 models, Environ. Res. Lett., 9, 104012, https://doi.org/10.1088/17489326/9/10/104012, 2014.

Coats, S., Cook, B. I., Smerdon, J. E., and Seager, R.: North American Pancontinental Droughts in Model Simulations of the Last Millennium, J. Climate, 28, 2025-2043, https://doi.org/10.1175/jcli-d-14-00634.1, 2015.

Cook, E. R. and Krusic, P. J.: Arstan, version 2005, Tree-ring laboratory, Lamont-Doherty Earth Obs., Palisades, NY, available at: http://www.ldeo.columbia.edu/trl (last access: 17 March 2014), 2005.

Cook, E. R., Briffa, K. R., Meko, D., Graybill, D. A., and Funkhouser, G.: The 'segment length curse' in long tree-ring chronology development for palaeoclimatic studies, Holocene, 5, 229-237, 1995.

Cook, E. R., Meko, D. M., Stahle, D. W., and Cleaveland, M. K.: Drought Reconstructions for the Continental United States, J. Climate, 12, 1145-1162, 1999.

Cook, E. R., Seager, R., Kushnir, Y., Briffa, K. R., Büntgen, U., Frank, D., Krusic, P. J., Tegel, W., van der Schrier, G., AndreuHayles, L., Baillie, M., Baittinger, C., Bleicher, N., Bonde, N., Brown, D., Carrer, M., Cooper, R., Čufar, K., Dittmar, C., Esper, J., Griggs, C., Gunnarson, B., Günther, B., Gutierrez, E., Haneca, K., Helama, S., Herzig, F., Heussner, K.-U., Hofmann, J., Janda, P., Kontic, R., Köse, N., Kyncl, T., Levanič, T., Linderholm, H., Manning, S., Melvin, T. M., Miles, D., Neuwirth,
B., Nicolussi, K., Nola, P., Panayotov, M., Popa, I., Rothe, A., Seftigen, K., Seim, A., Svarva, H., Svoboda, M., Thun, T., Timonen, M., Touchan, R., Trotsiuk, V., Trouet, V., Walder, F., Ważny, T., Wilson, R., and Zang, C.: Old World megadroughts and pluvials during the Common Era, Sci. Adv., 1, e1500561, https://doi.org/10.1126/sciadv.1500561, 2015.

Crowley, T. J. and Unterman, M. B.: Technical details concerning development of a $1200 \mathrm{yr}$ proxy index for global volcanism, Earth Syst. Sci. Data, 5, 187-197, https://doi.org/10.5194/essd5-187-2013, 2013.

D'Arrigo, R., Wilson, R., and Anchukaitis, K. J.: Volcanic cooling signal in tree ring temperature records for the past millennium, J. Geophys. Res.-Atmos., 118, 9000-9010, https://doi.org/10.1002/jgrd.50692, 2013.

Drobyshev, I., Niklasson, M., Linderholm, H. W., Seftigen, K., Hickler, T., and Eggertsson, O.: Reconstruction of a regional drought index in southern Sweden since AD 1750, Holocene, 21, 667-679, https://doi.org/10.1177/0959683610391312, 2011.

Dufresne, J. L., Foujols, M. A., Denvil, S., Caubel, A., Marti, O., Aumont, O., Balkanski, Y., Bekki, S., Bellenger, H., Benshila, R., Bony, S., Bopp, L., Braconnot, P., Brockmann, P., Cadule, P., Cheruy, F., Codron, F., Cozic, A., Cugnet, D., de Noblet, N., Duvel, J. P., Ethé, C., Fairhead, L., Fichefet, T., Flavoni, S., Friedlingstein, P., Grandpeix, J. Y., Guez, L., Guilyardi, E., Hauglustaine, D., Hourdin, F., Idelkadi, A., Ghattas, J., Joussaume, S., Kageyama, M., Krinner, G., Labetoulle, S., Lahellec, A., Lefebvre, M. P., Lefevre, F., Levy, C., Li, Z. X., Lloyd, J., Lott, F., Madec, G., Mancip, M., Marchand, M., Masson, S., Meurdesoif, Y., Mignot, J., Musat, I., Parouty, S., Polcher, J., Rio, C., Schulz, M., Swingedouw, D., Szopa, S., Talandier, C., Terray, P., Viovy, N., and Vuichard, N.: Climate change projections using the IPSL-CM5 Earth System Model: from CMIP3 to CMIP5, Clim. Dynam., 40, 2123-2165, https://doi.org/10.1007/s00382012-1636-1, 2013.

Esper, J., Frank, D. C., Timonen, M., Zorita, E., Wilson, R. J. S., Luterbacher, J., Holzkamper, S., Fischer, N., Wagner, S., Nievergelt, D., Verstege, A., and Buntgen, U.: Orbital forcing of treering data, Nat. Clim. Change, 2, 862-866, 2012.

Esper, J., Schneider, L., Smerdon, J. E., Schöne, B. R., and Büntgen, U.: Signals and memory in tree-ring width and density data, Dendrochronologia, 35, 62-70, https://doi.org/10.1016/j.dendro.2015.07.001, 2015.

Feng, S., Hu, Q., and Oglesby, R. J.: Influence of Atlantic sea surface temperatures on persistent drought in North America, Clim. Dynam., 37, 569-586, https://doi.org/10.1007/s00382010-0835-x, 2011.

Fischer, E. M., Luterbacher, J., Zorita, E., Tett, S. F. B., Casty, C., and Wanner, H.: European climate response to tropical volcanic eruptions over the last half millennium, Geophys. Res. Lett., 34, L05707, https://doi.org/10.1029/2006GL027992, 2007.

Frank, D. C., Esper, J., and Cook, E. R.: On variance adjustments in tree-ring chronology development, TRACE, 4, 56-66, 2006.

Franke, J., Frank, D., Raible, C. C., Esper, J., and Bronnimann, S.: Spectral biases in tree-ring climate proxies, Nat. Clim. Change, 3, 360-364, 2013.

Gao, C., Robock, A., and Ammann, C.: Volcanic forcing of climate over the past 1500 years: An improved ice core-based index for climate models, J. Geophys. Res.-Atmos., 113, D23111, https://doi.org/10.1029/2008JD010239, 2008. 
Gentine, P., Holtslag, A. A. M., D'Andrea, F., and Ek, M.: Surface and Atmospheric Controls on the Onset of Moist Convection over Land, J. Hydrometeorol., 14, 1443-1462, https://doi.org/10.1175/jhm-d-12-0137.1, 2013.

Gleckler, P. J., Wigley, T. M. L., Santer, B. D., Gregory, J. M., AchutaRao, K., and Taylor, K. E.: Volcanoes and climate: Krakatoa's signature persists in the ocean, Nature, 439, 675, https://doi.org/10.1038/439675, 2006.

Grinsted, A., Moore, J. C., and Jevrejeva, S.: Application of the cross wavelet transform and wavelet coherence to geophysical time series, Nonlin. Processes Geophys., 11, 561-566, https://doi.org/10.5194/npg-11-561-2004, 2004.

Gunnarson, B. E., Linderholm, H. W., and Moberg, A.: Improving a tree-ring reconstruction from west-central Scandinavia: 900 years of warm-season temperatures, Clim. Dynam., 36, 97108, https://doi.org/10.1007/s00382-010-0783-5, 2011.

Haarsma, R. J., Selten, F., v. Hurk, B., Hazeleger, W., and Wang, $\mathrm{X}$. .: Drier Mediterranean soils due to greenhouse warming bring easterly winds over summertime central Europe, Geophys. Res. Lett., 36, L04705, https://doi.org/10.1029/2008GL036617, 2009.

Harris, I., Jones, P. D., Osborn, T. J., and Lister, D. H.: Updated high-resolution grids of monthly climatic observations - the CRU TS3.10 Dataset, Int. J. Climatol., 34, 623-642, https://doi.org/10.1002/joc.3711, 2014.

Haurwitz, M. W. and Brier, G. W.: A Critique of the Superposed Epoch Analysis Method: Its Application to Solar-Weather Relations, Mon. Weather Rev., $\quad 109$, 2074-2079, https://doi.org/10.1175/15200493(1981)109<2074:acotse>2.0.co;2, 1981.

Hegerl, G. C., Black, E., Allan, R. P., Ingram, W. J., Polson, D., Trenberth, K. E., Chadwick, R. S., Arkin, P. A., Sarojini, B. B., Becker, A., Dai, A., Durack, P. J., Easterling, D., Fowler, H. J., Kendon, E. J., Huffman, G. J., Liu, C., Marsh, R., New, M., Osborn, T. J., Skliris, N., Stott, P. A., Vidale, P.-L., Wijffels, S. E., Wilcox, L. J., Willett, K. M., and Zhang, X.: Challenges in Quantifying Changes in the Global Water Cycle, B. Am. Meteorol. Soc., 96, 1097-1115, https://doi.org/10.1175/bams-d-13$00212.1,2015$.

Helama, S. and Lindholm, M.: Droughts and rainfall in south eastern Finland since AD 874, inferred from Scots pine tree-rings, Boreal Environ. Res., 8, 171-183, 2003.

Helama, S., Merilainen, J., and Tuomenvirta, H.: Multicentennial megadrought in northern Europe coincided with a global El Nino-Southern Oscillation drought pattern during the Medieval Climate Anomaly, Geology, 37, 175-178, https://doi.org/10.1130/g25329a.1, 2009.

Held, I. M. and Soden, B. J.: Robust Responses of the Hydrological Cycle to Global Warming, J. Climate, 19, 5686-5699, https://doi.org/10.1175/jcli3990.1, 2006.

Iles, C. E. and Hegerl, G. C.: Systematic change in global patterns of streamflow following volcanic eruptions, Nat. Geosci., 8, 838842, https://doi.org/10.1038/ngeo2545, 2015.

Iles, C. E., Hegerl, G. C., Schurer, A. P., and Zhang, X.: The effect of volcanic eruptions on global precipitation, J. Geophys. Res.Atmos., 118, 8770-8786, https://doi.org/10.1002/jgrd.50678, 2013.

Jones, P. D. and Lister, D. H.: The influence of the circulation on surface temperature and precipitation patterns over Europe,
Clim. Past, 5, 259-267, https://doi.org/10.5194/cp-5-259-2009, 2009.

Jones, P. D., Osborn, T. J., and Briffa, K. R.: Estimating Sampling Errors in Large-Scale Temperature Averages, J. Climate, 10, 2548-2568, https://doi.org/10.1175/15200442(1997)010<2548:eseils>2.0.co;2, 1997.

Jones, P. D., Melvin, T. M., Harpham, C., Grudd, H., and Helama, S.: Cool North European summers and possible links to explosive volcanic eruptions, J. Geophys. Res.-Atmos., 118, 6259-6265, https://doi.org/10.1002/jgrd.50513, 2013.

Jönsson, K. and Nilsson, C.: Scots Pine (pinus sylvestris L.) on Shingle Fields: A Dendrochronologic Reconstruction of Early Summer Precipitation in Mideast Sweden, J. Climate, 22, 47104722, https://doi.org/10.1175/2009jcli2401.1, 2009.

Jungclaus, J. H., Lohmann, K., and Zanchettin, D.: Enhanced 20thcentury heat transfer to the Arctic simulated in the context of climate variations over the last millennium, Clim. Past, 10, 22012213, https://doi.org/10.5194/cp-10-2201-2014, 2014.

Kavvada, A., Ruiz-Barradas, A., and Nigam, S.: AMO's structure and climate footprint in observations and IPCC AR5 climate simulations, Clim. Dynam., 41, 1345-1364, https://doi.org/10.1007/s00382-013-1712-1, 2013.

Landrum, L., Otto-Bliesner, B. L., Wahl, E. R., Conley, A., Lawrence, P. J., Rosenbloom, N., and Teng, H.: Last Millennium Climate and Its Variability in CCSM4, J. Climate, 26, 10851111, https://doi.org/10.1175/JCLI-D-11-00326.1, 2012.

Lehner, F., Joos, F., Raible, C. C., Mignot, J., Born, A., Keller, K. M., and Stocker, T. F.: Climate and carbon cycle dynamics in a CESM simulation from 850 to 2100 CE, Earth Syst. Dynam., 6, 411-434, https://doi.org/10.5194/esd-6-411-2015, 2015.

Linderholm, H. W. and Molin, T.: Early nineteenth century drought in east central Sweden inferred from dendrochronological and historical archives, Clim. Res., 29, 63-72, 2005.

Linderholm, H. W., Niklasson, M., and Molin, T.: Summer Moisture Variability in East Central Sweden Since the Mid-Eighteenth Century Recorded in Tree Rings, Geograf. Ann. A, 86, 277-287, https://doi.org/10.1111/j.0435-3676.2004.00231.x, 2004.

Linderholm, H. W., Björklund, J. A., Seftigen, K., Gunnarson, B. E., Grudd, H., Jeong, J.-H., Drobyshev, I., and Liu, Y.: Dendroclimatology in Fennoscandia - from past accomplishments to future potential, Clim. Past, 6, 93-114, https://doi.org/10.5194/cp6-93-2010, 2010.

Linderholm, H. W., Björklund, J., Seftigen, K., Gunnarson, B. E., and Fuentes, M.: Fennoscandia revisited: a spatially improved tree-ring reconstruction of summer temperatures for the last 900 years, Clim. Dynam., 45, 933-947, https://doi.org/10.1007/s00382-014-2328-9, 2014.

Madden, R. A. and Williams, J.: The Correlation between Temperature and Precipitation in the United States and Europe, Mon. Weather Rev., 106, 142-147, https://doi.org/10.1175/15200493(1978)106<0142:tcbtap>2.0.co;2, 1978.

McCarroll, D., Loader, N. J., Jalkanen, R., Gagen, M. H., Grudd, H., Gunnarson, B. E., Kirchhefer, A. J., Friedrich, M., Linderholm, H. W., Lindholm, M., Boettger, T., Los, S. O., Remmele, S., Kononov, Y. M., Yamazaki, Y. H., Young, G. H., and Zorita, E.: A 1200-year multiproxy record of tree growth and summer temperature at the northern pine forest limit of Europe, Holocene, 23, 471-484, https://doi.org/10.1177/0959683612467483, 2013. 
Melvin, T. M. and Briffa, K. R.: A "signal-free" approach to dendroclimatic standardisation, Dendrochronologia, 26, 71-86, https://doi.org/10.1016/j.dendro.2007.12.001, 2008.

National Research Council: Surface Temperature Reconstructions for the Last 2,000 Years, The National Academies Press, Washington, D.C., 1-160, 2006.

Oglesby, R., Feng, S., Hu, Q., and Rowe, C.: The role of the Atlantic Multidecadal Oscillation on medieval drought in North America: Synthesizing results from proxy data and climate models, Global Planet. Change, 84-85, 56-65, https://doi.org/10.1016/j.gloplacha.2011.07.005, 2012.

Osborn, T. J.: Simulating the winter North Atlantic Oscillation: the roles of internal variability and greenhouse gas forcing, Clim. Dynam., 22, 605-623, https://doi.org/10.1007/s00382004-0405-1, 2004.

Otto-Bliesner, B. L., Brady, E. C., Fasullo, J., Jahn, A., Landrum, L., Stevenson, S., Rosenbloom, N., Mai, A., and Strand, G.: Climate Variability and Change since $850 \mathrm{CE}$ : An Ensemble Approach with the Community Earth System Model, B. Am. Meteorol. Soc., 97, 735-754, https://doi.org/10.1175/bams-d-14-00233.1, 2016.

Sarojini, B. B., Stott, P. A., and Black, E.: Detection and attribution of human influence on regional precipitation, Nat. Clim. Change, 6, 669-675, https://doi.org/10.1038/nclimate2976, 2016.

Schmidt, G. A., Jungclaus, J. H., Ammann, C. M., Bard, E., Braconnot, P., Crowley, T. J., Delaygue, G., Joos, F., Krivova, N. A., Muscheler, R., Otto-Bliesner, B. L., Pongratz, J., Shindell, D. T., Solanki, S. K., Steinhilber, F., and Vieira, L. E. A.: Climate forcing reconstructions for use in PMIP simulations of the last millennium (v1.0), Geosci. Model Dev., 4, 33-45, https://doi.org/10.5194/gmd-4-33-2011, 2011.

Seftigen, K., Linderholm, H. W., Drobyshev, I., and Niklasson, M.: Reconstructed drought variability in southeastern Sweden since the 1650s, Int. J. Climatol., 33, 2449-2458, https://doi.org/10.1002/joc.3592, 2013.

Seftigen, K., Björklund, J., Cook, E. R., and Linderholm, H. W.: A tree-ring field reconstruction of Fennoscandian summer hydroclimate variability for the last millennium, Clim. Dynam., 44, 3141-3154, https://doi.org/10.1007/s00382-014-2191-8, 2014.

Seftigen, K., Cook, E., Linderholm, H., Fuentes, M., and Björklund, J.: The Potential of Deriving Tree-Ring-Based Field Reconstructions of Droughts and Pluvials over Fennoscandia, J. Climate, 28, 3453-3471, https://doi.org/10.1175/JCLI-D-13-00734.s1, 2015.

Seneviratne, S. I., Corti, T., Davin, E. L., Hirschi, M., Jaeger, E. B., Lehner, I., Orlowsky, B., and Teuling, A. J.: Investigating soil moisture-climate interactions in a changing climate: A review, Earth-Sci. Rev., 99, 125-161, https://doi.org/10.1016/j.earscirev.2010.02.004, 2010.

Shindell, D. T., Schmidt, G. A., Mann, M. E., and Faluvegi, G.: Dynamic winter climate response to large tropical volcanic eruptions since 1600, J. Geophys. Res.-Atmos., 109, D05104, https://doi.org/10.1029/2003JD004151, 2004.

Sigl, M., Winstrup, M., McConnell, J. R., Welten, K. C., Plunkett, G., Ludlow, F., Buntgen, U., Caffee, M., Chellman, N., Dahl-Jensen, D., Fischer, H., Kipfstuhl, S., Kostick, C., Maselli, O. J., Mekhaldi, F., Mulvaney, R., Muscheler, R., Pasteris, D. R., Pilcher, J. R., Salzer, M., Schupbach, S., Steffensen, J. P., Vinther, B. M., and Woodruff, T. E.: Timing and climate forc- ing of volcanic eruptions for the past 2,500 years, Nature, 523, 543-549, 2015.

Taylor, K. E., Stouffer, R. J., and Meehl, G. A.: An Overview of CMIP5 and the Experiment Design, B. Am. Meteorol. Soc., 93, 485-498, https://doi.org/10.1175/bams-d-11-00094.1, 2012.

Thiéblemont, R., Matthes, K., Omrani, N.-E., Kodera, K., and Hansen, F.: Solar forcing synchronizes decadal North Atlantic climate variability, Nature communications, 6, 8268, 2015.

Thomson, D. J.: Spectrum estimation and harmonic analysis, Proc. IEEE, 70, 1055-1096, https://doi.org/10.1109/PROC.1982.12433, 1982.

Thornthwaite, C. W.: An Approach toward a Rational Classification of Climate, Geogr. Rev., 38, 55-94, https://doi.org/10.2307/210739, 1948.

Tolwinski-Ward, S., Evans, M. N., Hughes, M. K., and Anchukaitis, K. J.: An efficient forward model of the climate controls on interannual variation in tree-ring width, Clim. Dynam., 36, 24192439, https://doi.org/10.1007/s00382-010-0945-5, 2011.

Trenberth, K. E.: Changes in precipitation with climate change, Clim. Res., 47, 123-138, https://doi.org/10.3354/cr00953, 2011.

van Oldenborgh, G. J. and Van Ulden, A. A. D.: On the relationship between global warming, local warming in the Netherlands and changes in circulation in the 20th century, Int. J. Climatol., 23, 1711-1724, https://doi.org/10.1002/joc.966, 2003.

Vicente-Serrano, S. M., Beguería, S., and López-Moreno, J. I.: A Multiscalar Drought Index Sensitive to Global Warming: The Standardized Precipitation Evapotranspiration Index, J. Climate, 23, 1696-1718, https://doi.org/10.1175/2009jcli2909.1, 2010.

Vicente-Serrano, S. M., Gouveia, C., Camarero, J. J., Beguería, S., Trigo, R., López-Moreno, J. I., Azorín-Molina, C., Pasho, E., Lorenzo-Lacruz, J., Revuelto, J., Morán-Tejeda, E., and SanchezLorenzo, A.: Response of vegetation to drought time-scales across global land biomes, P. Natl. Acad. Sci. USA, 110, 52-57, https://doi.org/10.1073/pnas.1207068110, 2013.

Watanabe, S., Hajima, T., Sudo, K., Nagashima, T., Takemura, T., Okajima, H., Nozawa, T., Kawase, H., Abe, M., Yokohata, T., Ise, T., Sato, H., Kato, E., Takata, K., Emori, S., and Kawamiya, M.: MIROC-ESM 2010: model description and basic results of CMIP5-20c3m experiments, Geosci. Model Dev., 4, 845-872, https://doi.org/10.5194/gmd-4-845-2011, 2011.

Wigley, T. M. L., Briffa, K. R., and Jones, P. D.: On the Average Value of Correlated Time Series, with Applications in Dendroclimatology and Hydrometeorology, J. Clim. Appl. Meteorol., 23, 201-213, https://doi.org/10.1175/15200450(1984)023<0201:otavoc>2.0.co;2, 1984.

Wilson, R., Miles, D., Loader, N. J., Melvin, T., Cunningham, L., Cooper, R., and Briffa, K.: A millennial long March-July precipitation reconstruction for southern-central England, Clim. Dynam., 40, 997-1017, https://doi.org/10.1007/s00382-012-1318z, 2012.

Wilson, R., Anchukaitis, K., Briffa, K. R., Büntgen, U., Cook, E., D’Arrigo, R., Davi, N., Esper, J., Frank, D., Gunnarson, B., Hegerl, G., Helama, S., Klesse, S., Krusic, P. J., Linderholm, H. W., Myglan, V., Osborn, T. J., Rydval, M., Schneider, L., Schurer, A., Wiles, G., Zhang, P., and Zorita, E.: Last millennium northern hemisphere summer temperatures from tree rings: Part I: The long term context, Quaternary Sci. Rev., 134, 1-18, https://doi.org/10.1016/j.quascirev.2015.12.005, 2016. 
Wu, P., Christidis, N., and Stott, P.: Anthropogenic impact on Earth's hydrological cycle, Nat. Clim. Change, 3, 807-810, 2013. Wu, T., Song, L., Li, W., Wang, Z., Zhang, H., Xin, X., Zhang, Y., Zhang, L., Li, J., Wu, F., Liu, Y., Zhang, F., Shi, X., Chu, M., Zhang, J., Fang, Y., Wang, F., Lu, Y., Liu, X., Wei, M., Liu, Q., Zhou, W., Dong, M., Zhao, Q., Ji, J., Li, L., and Zhou, M.: An overview of BCC climate system model development and application for climate change studies, J. Meteorol. Res., 28, 34-56, https://doi.org/10.1007/s13351-014-3041-7, 2014.
Zhang, H., Yuan, N., Esper, J., Werner, J. P., Xoplaki, E., Büntgen, U., Treydte, K., and Luterbacher, J.: Modified climate with long term memory in tree ring proxies, Environ. Res. Lett., 10, 084020, https://doi.org/10.1088/1748-9326/10/8/084020, 2015.

Zhang, X., Zwiers, F. W., Hegerl, G. C., Lambert, F. H., Gillett, N. P., Solomon, S., Stott, P. A., and Nozawa, T.: Detection of human influence on twentieth-century precipitation trends, Nature, 448, 461-465, 2007. 